\title{
Desenvolvimento de Algoritmos Paralelos para Aglomerados com a Técnica de Paralelização de Laços
}

Ulisses Kendi Hayashida

\author{
DISSERTAÇÃO APRESENTADA \\ $\mathrm{AO}$ \\ INSTITUTO DE MATEMÁTICA E ESTATÍSTICA \\ DA \\ UNIVERSIDADE DE SÃO PAULO \\ PARA \\ OBTENÇAO DO GRAU DE MESTRE \\ EM \\ CIÊNCIA DA COMPUTAÇÃO
}

Área de Concentração: Ciência da Computação

Orientador: Prof. Dr. Siang Wun Song

Durante o desenvolvimento deste trabalho, o autor recebeu apoio financeiro da CAPES

- São Paulo, março de 2005 - 


\section{Desenvolvimento de Algoritmos Paralelos para Aglomerados com a Técnica de Paralelização de Laços}

Este exemplar corresponde à redação final da dissertação devidamente corrigida e defendida por Ulisses Kendi Hayashida e aprovada pela comissão julgadora.

São Paulo, março de 2005

Banca examinadora:

Prof. Dr. Siang Wun Song (orientador) IME-USP

Prof. Dr. Kunio Okuda

IME-USP

Prof. Dr. Jairo Panetta

CPTEC-INPE 


\section{Agradecimentos}

Agradeço à minha família pelo apoio e compreensão durante o mestrado.

Também agradeço ao meu orientador Siang Wun Song pela sua excepcional ajuda e paciência. Agradeço todo o material emprestado, as reuniões, as dicas, e os sábios conselhos.

Agradeço ao professor Kunio Okuda pelas colaborações acadêmicas, e pelo apoio prestado. Agradeço a presença nas reuniões junto com o professor Siang, as dicas, e os também sábios conselhos.

Agradeço ao Jairo Panetta pela presença na defesa de dissertação, e pelo material sobre Transformadas de Legendre.

Pela presença no meu exame de qualificação e pela ajuda acadêmica, agradeço ao professor Alfredo Goldman.

Durante o mestrado, também tive ajuda de meus colegas do IMESCOS ${ }^{\mathrm{TM}}$, e do pessoal da rede LCPD, em especial o Braga, pelas longas horas em que me ajudou resolvendo problemas de configurações na rede e pelas valiosas dicas de Linux.

Agradeço também a Martha, que cuidava do Beowulf do IME/USP e ajudou na configuração do Beowulf.

Ao pessoal da Secretaria de Pós Graduação pela agilidade e eficiência nas questões burocráticas, em especial a Patricia, que sempre atendeu muito bem a todos.

Agradeço à CAPES pelo apoio financeiro. 
A grande maioria das aplicações para aglomerados (clusters e grades de computação) são trivialmente paralelas, com muito pouca ou quase nenhuma demanda na comunicação. Mostraremos que usando o método de transformação de dependências, originalmente proposto para elaborar arranjos sistólicos VLSI, podemos gerar algoritmos paralelos não triviais para aglomerados, após alguma adaptação. Ilustraremos o método usando o algoritmo sistólico de multiplicação de matrizes, o qual pode ser adaptado para solucionar as Transformadas de Legendre. As Transformadas de Legendre são a parte que mais consome tempo nos modelos de circulação atmosférica, sendo muito usado na previsão do tempo. O algoritmo de multiplicação de matrizes considera o produto de duas matrizes $n \times n$ como a multiplicação de duas matrizes $p \times p$ cujos elementos são submatrizes $n / p \times n / p$. Para $m$ multiplicações, usando $p^{2}$ processadores, a solução paralela proposta requer um total de $(m+2) p-2$ passos de computação e comunicação envolvendo submatrizes. O algoritmo seqüencial de multiplicação requer $m p^{3}$ passos de computação envolvendo submatrizes. Obtivemos um speedup em termos de passos de computação de $\frac{m p^{3}}{(m+2) p-2}$ ou aproximadamente $p^{2}$. Obtivemos portanto um speedup linear. Isto é confirmado pelos experimentos em uma máquina paralela do tipo Beowulf de 16 nós e também em um aglomerado de 18 micromputadores disponíveis em laboratórios de alunos de pós-graduação. O método proposto também foi aplicado ao problema de similaridade ou alinhamento de cadeias. Apresentaremos também resultados experimentais promissores para essa aplicação. 
Most parallel applications in agglomerates (cluster and grid computing) are based on trivially parallelized algorithms with very low or hardly any demand on communication. The purpose of this work is two-fold. First we show that by using the dependence transformation method, originally proposed to design VLSI systolic arrays, we can generate non trivial parallel algorithms for cluster or grid computing, after some suitable adaptation. Second we illustrate this method by obtaining a systolic matrix product algorithm that can be adapted to solve Legendre Transforms, the most time-consuming part of global atmospheric circulation models, the workhorse of weather forecasting. The algorithm views the product of two $n \times n$ matrices as multiplying two $p \times p$ matrices whose elements are $n / p \times n / p$ submatrices. For $m$ such multiplications, using $p^{2}$ processors, the proposed parallel solution requires a total of $(m+2) p-2$ computing steps and communication steps involving submatrices. The trivial sequential multiplication algorithm requires $m p^{3}$ computing steps involving submatrices. We obtain a speedup in terms of computing steps of $\frac{m p^{3}}{(m+2) p-2}$ or roughly $p^{2}$. We thus obtain linear speedup. This is confirmed by experiments run on a 16-node Beowulf machine and also on a cluster of 18 microcomputers available in a graduate student laboratory. The proposed method was also applied to obtain the similarity or alignment of two strings. We also present promising experimental results for this application. 


\section{Sumário}

1 Introdução 1

1.1 Motivação . . . . . . . . . . . . . . . . . . . . . . 1

1.2 Paralelismo . . . . . . . . . . . . . . . . . . 4

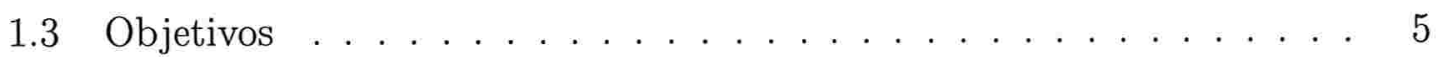

1.4 Arranjos Sistólicos . . . . . . . . . . . . . . . . 6

1.5 Organização da Dissertação . . . . . . . . . . . . . . . . . . 7

2 Grades de Computação $\quad 9$

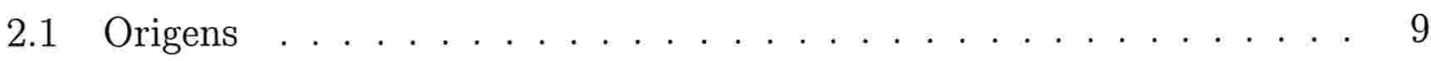

$2.2 \mathrm{Usos} \ldots \ldots \ldots \ldots \ldots \ldots \ldots$

2.3 Aplicações Paralelas . . . . . . . . . . . . . . . . . . . . 11

2.4 O projeto IMPAR/InteGrade . . . . . . . . . . . . . . . . 12

3 Arranjos Sistólicos $\quad 14$

4 Transformações de dependências $\quad 17$

4.1 Equações de Recorrência Uniformes . . . . . . . . . . . . . . . . . 18

4.2 Função de Tempo $\tau$. . . . . . . . . . . . . . . . . . . . . . 20

4.3 Função de Alocação $\alpha \ldots \ldots$. . . . . . . . . . . . . . . . . . 26 
5.1 Sincronização . . . . . . . . . . . . . . . . . . . . . . . . . 34

5.2 Granularidade . . . . . . . . . . . . . . . . . 35

5.2 .1 Transformadas de Legendre . . . . . . . . . . . . . . . . 39

5.3 Tolerância a Falhas . . . . . . . . . . . . . . . . . . . . . . . . . . 39

5.4 Heterogeneidade de Hardware . . . . . . . . . . . . . . . . . . . 40

6 Similaridade $\quad 42$

7 Resultados experimentais $\quad 45$

7.1 Multiplicação de Matrizes . . . . . . . . . . . . . . . . . . 46

7.1 .1 No Beowulf . . . . . . . . . . . . . . . . . . 446

7.1 .2 Na Grade de Desktops . . . . . . . . . . . . . . . 50

7.2 Similaridade ou Alinhamento de Cadeias . . . . . . . . . . . . . . 53

7.2.1 Resultados no Beowulf . . . . . . . . . . . . 53

7.2 .2 Resultados no InteGrade . . . . . . . . . . . . . . . . 56

$\begin{array}{lll}8 & \text { Conclusão } & 58\end{array}$

8.1 Trabalhos Futuros . . . . . . . . . . . . . . . 60 


\section{Capítulo 1}

\section{Introdução}

Por um longo tempo, o aumento na velocidade dos circuitos digitais foi expressivo o suficiente para suprir a demanda de desempenho requerida pela grande maioria dos problemas computacionais existentes [19]. Desta forma, os fabricantes de computadores mantiveram-se focados quase que exclusivamente na construção de computadores seguindo uma organização seqüencial. Ou seja, o objetivo principal era o de construir componentes computacionais de poder cada vez mais elevado apenas aumentando a freqüência de operação dos componentes de processamento.

Os desenvolvedores de software, por sua vez, mantiveram-se focados no desenvolvimento de programas seguindo uma organização seqüencial. Ou seja, para acompanhar os fabricantes de computadores, focaram-se na criação de softwares seqüenciais que acompanhassem o aumento de poder de processamento dos componentes computacionais.

Os altos custos de desenvolver uma máquina paralela somados aos altos custos da criação de softwares para programação paralela e distribuída não se justificavam para uma produção em maior escala. Mais tarde, porém, diversos fatores motivaram o surgimento da computação paralela, conforme será discutido a seguir.

\subsection{Motivação}

Apesar do crescente aumento de poder computacional dos atuais componentes de processamento, tem-se notado cada vez mais que a abordagem seqüencial de aumento de desempenho, apesar de importante, não é mais o suficiente para suprir a 
demanda computacional [19].

Ainda que o aumento de desempenho dos processadores esteja seguindo a famosa "Lei de Moore" [46], em que o poder de processamento dos processadores dobra a cada 18 meses, é cada vez mais comum o aparecimento de problemas computacionais que consomem enormes quantidades de recursos computacionais que não podem ser atendidos por computadores atualmente disponíveis. Como exemplo, temos os chamados "problemas computacionalmente pesados", que são problemas que exigem uma quantidade substancial de poder computacional. Podemos citar vários exemplos, tais como previsão do tempo, manipulação de multimídia (áudio, vídeo, TV interativa), prospeção de petróleo, simulações mercadológicas, simulações de mercado financeiro e problemas NP difíceis.

Adicionalmente, com o mundo ficando cada vez mais competitivo, um problema que vem se agravando ao passar do tempo é a necessidade de soluções cada vez mais rápidas e precisas. No caso de prospecção de petróleo, além da questão do tempo, a precisão da solução é fundamental para evitar desperdícios de recursos com perfurações errôneas ou infrutíferas, e assim perder milhões de dólares. No exemplo de previsão do tempo, as pessoas que fossem passear em um final de semana gostariam de saber como estará o tempo pelo menos alguns dias antes, e com a maior precisão possível. Similarmente pode-se imaginar o mesmo para os exemplos restantes. Para tais problemas ocorre que quanto maior for a restrição de tempo, menos preciso será a resposta. E quanto maior for a restrição de precisão, mais tempo de computação será necessário. O modo mais viável de se obter uma resposta razoável em tempo hábil seria aumentando o poder computacional.

Com a exigência computacional dos problemas atuais podendo crescer mais que o dobro a cada 18 meses, e portanto mais do que prevê a "Lei de Moore", é natural imaginar que em algum momento haveria um encontro entre as curvas da Lei de Moore e a de Exigência Computacional, tal como ilustra o gráfico 1.1.

Poderia-se argumentar que a solução para a demanda cada vez maior de poder computacional seria elevar a taxa de aumento de desempenho dos circuitos e assim construir componentes de processamento mais velozes, com um aumento de desempenho compatível às atuais exigências computacionais. Porém, segundo as leis da física, a atual tecnologia de transistores de silício parece estar chegando no limite. Isso ocorre em função da utilização de um número cada vez maiz reduzido de átomos de silício na confecção de um único transistor. Dessa forma podem caber mais transistores em um processador e assim obter-se mais desempenho. Porém há 


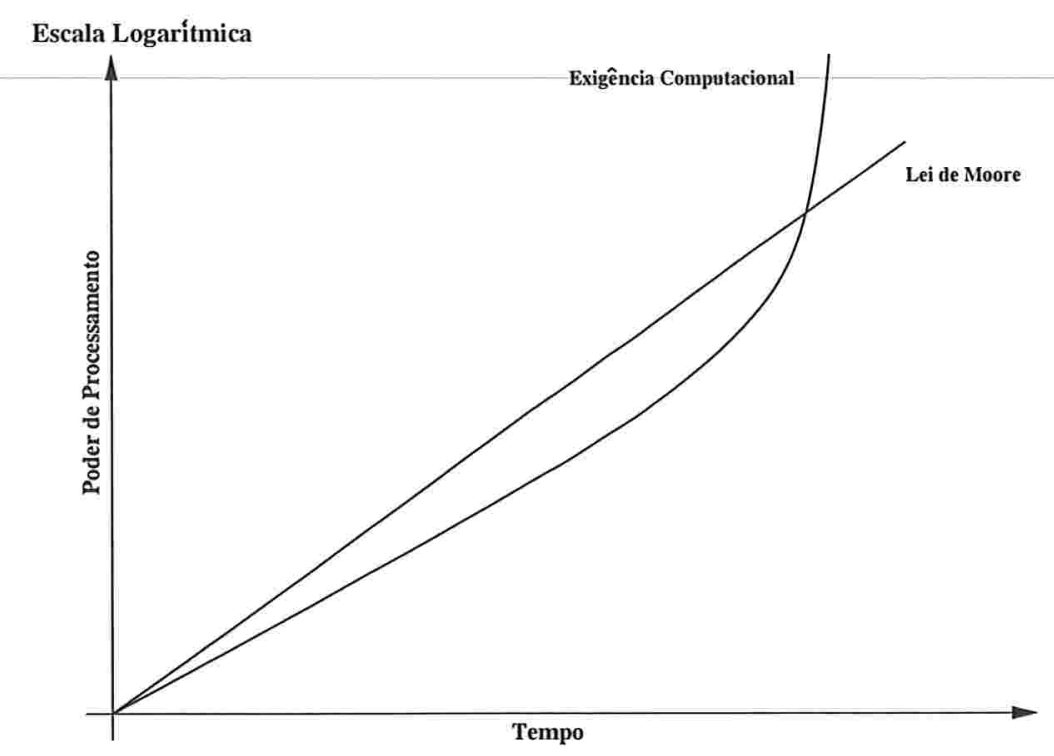

Figura 1.1: Curva de Lei de Moore $\times$ Exigência Computacional

um número mínimo de átomos para que as propriedades semicondutoras do silício continuem a funcionar de modo ideal.

Alternativamente, existem novas tecnologias sendo estudadas, como os "nanotubos" e os "processadores quânticos", que não usam silício. Porém, tais tecnologias ainda se encontram em fase experimental. Esse limite na tecnologia de silício mostra que até mesmo a "Lei de Moore" pode estar com os dias contados, caso não surjam novas tecnologias. Antes mesmo de se chegar ao limite físico teórico, há na prática o problema da dissipação de calor e problema de potência. Pode-se notar que os ventiladores acoplados aos processadores estão ficando cada vez maiores, com os processadores ficando cada vez mais potentes.

Uma outra questão que se deve levar em conta é o crescente número de softwares rodando ao mesmo tempo nos computadores pessoais. Como exemplo podemos citar o sistema operacional, aplicações de multimídia, jogos em 3 dimensões, antivírus e firewalls. Tais softwares ficam rodando todos ao mesmo tempo, de forma aparentemente simultânea. Para dar essa sensação de simultaneidade, tais softwares ficam na realidade concorrendo pelo uso do processador, memória e canais de comunicação. Por isso, é comum notarmos travamentos e oscilações de desempenho nos computadores pessoais. Até o momento a "Lei de Moore" foi o suficiente para satisfazer os computadores pessoais e suas aplicações de uso geral, mas parece estar chegando o dia em que a "Lei de Moore" não satisfará nem mesmo os computadores pessoais. 
Dessa forma, o paralelismo é visto como a forma mais viável de se obter mais desempenho, e é a forma mais usada atualmente. Como exemplo, basta acessar o site do TOP 500 [48]. O site lista os 500 computadores mais poderosos do mundo atualmente. Todos os computadores listados são paralelos.

\subsection{Paralelismo}

O conceito de paralelismo pode ser visto como uma forma alternativa de se obter maior velocidade de computação. A maneira tradicional de se obter mais velocidade consiste basicamente em aumentar a velocidade de operação dos circuitos digitais. Em computação paralela, no entanto, o aumento de velocidade resulta da execução simultânea de operações. Para isso é necessário um número maior de componentes de processamento e alguma forma de paralelizar o problema. Além disso, deve ser feito de forma a se obter um desempenho superior ao da versão seqüencial.

Algoritmos paralelos são mais complexos de se elaborar. Deve-se levar em conta diversos fatores a fim de se obter o melhor desempenho possível. Neste trabalho não serão discutidos em detalhes os modelos padrões de computação paralela e distribuída, subentendendo-se que o leitor já disponha de conhecimento prévio quanto a termos como speedup, latência, tempo de computação, tempo de comunicação, largura de banda, sincronização, etc. Para um estudo mais profundo do assunto, sugere-se a leitura de [1].

Como maneira de implementar a solução paralela, inicialmente investiu-se na construção de supercomputadores paralelos com dezenas e até centenas de processadores interligados através de um sofisticado sistema de interconexão. Mais tarde, com o barateamento dos computadores pessoais, surgiram os clusters de computadores, que são amontoados de computadores interligados em rede via ethernet.

Devido a popularização dos computadores pessoais e a crescente melhoria do desempenho das redes de computadores, e dos recursos computacionais em geral, teve-se a idéia de se utilizar computadores independentes conectados em rede como plataforma de execução de aplicações paralelas. Originou-se assim a área de grades de computação (grid computing). Os principais atrativos desta idéia são a possibilidade de alocar uma enorme quantidade de recursos (e.g. centenas de milhares de computadores conectados via Internet, como no SETI [31]) a uma aplicação paralela e fazê-lo a um custo muito menor do que alternativas tradicionais, baseadas em clusters e supercomputadores paralelos. Além de utilizar computadores inde- 
pendentes, visa-se inclusive adicionar os clusters e supercomputadores já existentes. Isso torna possível resolver problemas que exigem um grande poder computacional ou capacidade de armazenamento a um menor custo, usando equipamentos já adquiridos, e portanto sem a necessidade da compra de caros supercomputadores paralelos ou equipamentos especializados. No capítulo 2 há maiores informações sobre grades de computação, inclusive com informações sobre a grade de computação do IME/USP [28].

No restante do texto, usaremos o termo aglomerados para nos referir tanto a clusters como a grades de computação, nos casos em que não seja necessário diferenciar um ou outro. Caso contrário, usaremos os termos específicos cluster e grades de computação.

\subsection{Objetivos}

A maioria das aplicações paralelas executando hoje em aglomerados, principalmente no caso de grades de computação, são trivialmente paralelizáveis e geralmente baseadas em um processador central que envia tarefas para um conjunto de processadores sempre que estes se encontram livres para realizar mais tarefas. Esse esquema é conhecido pelo nome de bag of tasks. Os exemplos mais conhecidos de tais aplicações são o SETI [31], a procura por números primos de Mersenne [45] e processamento de imagens [47].

Neste trabalho pretendemos propor um método para desenvolver aplicações não trivialmente paralelizáveis e com propriedades desejáveis para executar em um aglomerado qualquer. O método é baseado em uma técnica anteriormente proposta para síntese de algoritmos sistólicos. Estes algoritmos eram usados em projetos de circuitos VLSI ( Very Large Scale Integration), implementados em pastilhas de silício.

Basicamente, o que o método faz é criar algoritmos paralelos a partir de laços aninhados. Mais especificamente, dado um algoritmo seqüencial que contenha laços aninhados, inicialmente o método analisa as dependências entre as iterações do algoritmo, ou seja, analisa como cada iteração depende de outra, resultando nos vetores de dependência ${ }^{1}$. Depois cria todo um arcabouço necessário para rodar eficientemente esse algoritmo em paralelo, através das funções de tempo e de alocação ${ }^{2}$. O resultado final do método é o que se chama de arranjo sistólico (systolic array), os

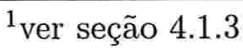

${ }^{2}$ ver seções 4.2 e 4.3
} 
quais são apropriados no projeto de circuitos VLSI mas que podem ser modificados para se adequar a um aglomerado.

No capítulo 4 ilustraremos o método usando o algoritmo sistólico de multiplicação de matrizes e o de similaridade ou alinhamento de cadeias. O algoritmo de multiplicação considera o produto de duas matrizes $n \times n$ como multiplicando duas matrizes $p \times p$ cujos elementos são submatrizes $n / p \times n / p$. Para $m$ multiplicações, usando $p^{2}$ processadores, a solução paralela proposta requer um total de $(m+2) p-2$ passos de computação e comunicação envolvendo submatrizes. O algoritmo seqüencial de multiplicação requer $m p^{3}$ passos de computação envolvendo submatrizes. Obtivemos um speedup em termos de passos de computação de $\frac{m p^{3}}{(m+2) p-2}$ ou aproximadamente $p^{2}$. Obtivemos portanto um speedup linear. Isto é confirmado pelos experimentos em uma máquina paralela do tipo Beowulf de 16 nós e também em um aglomerado de 18 micromputadores. O problema de similaridade ou alinhamento de cadeias, descrito no capítulo 6 , também obteve resultados experimentais promissores.

O algoritmo sistólico de multiplicação de matrizes pode ser adaptado para solucionar as Transformadas de Legendre. As Transformadas de Legendre são a parte que mais consome tempo nos modelos de circulação atmosférica, sendo muito usado na previsão do tempo. Na seção 5.2.1 serão dados maiores informações sobre Trasnformadas de Legendre.

Os detalhes serão apresentados neste trabalho.

\subsection{Arranjos Sistólicos}

Alguns argumentos a favor de arranjos sitólicos são a regularidade da disposição dos elementos de processamento e comunicação de cada elemento de processamento com poucos elementos vizinhos. Ou seja, não há um elemento central comunicando-se com todos os elementos de processamento. Tais propriedades são apropriadas para uma implementação em grades de computação, onde queremos evitar primitivas de comunicação custosas tais como um broadcast ou um all-to-all, que despenderia muita comunicação em uma grade com muitos elementos. Mesmo em um cluster isso seria vantajoso, pois a minimização da comunicação é a melhor forma de se obter mais desempenho em uma aplicação paralela [1].

Porém, as computações envolvidas em um arranjo sistólico são de granularidade 
fina, o que exigiria um maior número relativo de comunicações. Como solução seria necessário modificar as computações para granularidade grossa, diminuindo assim o número de comunicações em uma grade. Isto será ilustrado através dos exemplos de multiplicação de matrizes e de similaridade ou alinhamento de cadeias.

Existem ainda outros problemas em arranjos sitólicos, como a freqüente sincronização das computações e a exigência da homogeneidade de desempenho dos elementos de processamento de um circuito VLSI que implemente um arranjo sistólico. Em um aglomerado de muitos elementos, seria muito custoso fazer várias sincronizações. Além disso, isso seria agravado com a heterogeneidade de hardware, algo comum de ser encontrado em um aglomerado, principalmente em grades. O desempenho de uma aplicação seria ditado pelo elemento de processamento mais lento.

\subsection{Organização da Dissertação}

No capítulo 2 será dada uma breve descrição de grades de computação, baseado em Foster [25], Cirne [26] e Goldchleger [27]. Tal descrição se faz necessária para melhor contextualizar nosso trabalho. Falaremos sobre sua origem, vantagens, características, e ilustraremos o seu uso através de alguns exemplos. Também será discutida a grade de computação do projeto IMPAR/InteGrade[28], que é a grade que esta sendo elaborada pelo IME-USP, e sobre a qual foram feitos parte dos testes de desempenho dos algoritmos sistólicos.

No capítulo 3 falaremos um pouco mais sobre arranjos sistólicos e mostraremos sua ligação com aglomerados. Salientaremos algumas características que o tornam apropriadas para um aglomerado, e explicaremos como contornar as características não apropriadas, de forma a ajustá-la para um aglomerado.

No capítulo 4 continuaremos com a especificação de um algoritmo por um sistema de equações de recorrências, baseado em Song [29]. Neste capítulo será estudado como projetar algoritmos paralelos a partir de laços aninhados. Este capítulo é portanto a base de todo trabalho, contendo várias definições, fórmulas e teoremas necessários para um melhor entendimento do método de paralelização de laços. Serão estudadas Equações de Recorrência Uniforme (ERU), grafo de dependências, função de tempo e função de alocação. Foram feitas várias figuras e exemplos ilustrativos a fim de ajudar a melhorar o entendimento, pois trata-se de uma parte mais teórica e complexa. 
No capítulo 5 será mostrado como adaptar o método descrito no capítulo 4 para uso em aglomerados. Serão mostrados os exemplos de multiplicação de matrizes e no capítulo 6 o exemplo de similaridade ou alinhamento de cadeias. No nosso trabalho, a adaptação consistirá em aumentar a granularidade e usar de bibliotecas de comunicação para a sincronização. Serão dados algumas outras idéias de adaptação quanto a tolerância a falhas e heterogeneidade da grade, porém isto não será implementado em nosso trabalho.

No capítulo 6 será definido o problema de similaridade ou alinhamento de cadeias. O capítulo trata do algoritmo de similaridade, o qual é utilizado para calcular a similaridade entre duas cadeias de DNA. Será descrito como elaborar o algoritmo sistólico para solucionar o problema, com as adaptações descritas no capítulo 5.

No capítulo 7 serão dados alguns gráficos dos tempos e dos speedups para a implementação do algoritmo de multiplicação de matrizes e do algoritmo de similaridade ou alinhamento de cadeias. Os algoritmos foram implementados na linguagem $\mathrm{C}$, alguns usando a biblioteca MPI (Message Passage Interface) e outros a biblioteca BSP (Bulk Synchronous Parallel). Os algoritmos implementados em MPI foram rodados em um Beowulf de 16 nós [35], e também na rede LCPD [50] (Laboratório de Computação Paralela e Distribuída). Os algoritmos implementados em BSP foram rodados nas redes LCPD e Eclipse [51], utilizando a grade do projeto IMPAR [28]. Os resultados obtidos no Beowulf foram muito bons, com speedups superlineares. Os resultados utilizando o BSP sobre o IMPAR foram razoáveis, se for levado em conta que foram utilizadas as duas redes distintas LCPD e Eclipse.

No capítulo 8 serão colocadas as conclusões do trabalho, assim como possíveis trabalhos a serem realizados no futuro.

A bibliografia encontra-se no final do trabalho. 


\section{Capítulo 2}

\section{Grades de Computação}

Neste capítulo objetiva-se dar uma visão geral de grades de computação. Para um estudo mais profundo sugere-se a leitura de Foster [25]. Este capítulo é baseado nos trabalhos de Foster [25], Cirne [26] e Goldchleger [27].

\subsection{Origens}

Devido a crescente melhoria do desempenho das redes de computadores, e dos recursos computacionais em geral, teve-se a idéia de se utilizar computadores independentes conectados em rede como plataforma de execução de aplicações paralelas, originando-se a área de grades de computação.

Os principais atrativos desta idéia são a possibilidade de alocar uma enorme quantidade de recursos (e.g. centenas de milhares de computadores conectados via Internet, como no SETI [31]) a uma aplicação paralela e fazê-lo a um custo muito menor do que alternativas tradicionais (baseadas em supercomputadores paralelos).

As vantagens potenciais da grade de computação têm atraído muita atenção para a área. Nos últimos anos, grandes projetos (como Globus [38], Legion [41, 43] e Condor [39]) foram iniciados para materializar a visão de grades de computação e aplicações foram desenvolvidas, das quais, a mais conhecida é o SETI [31].

O estudo de grades de computação é uma área recente e em franca expansão. O que começou em universidades e institutos de pesquisa ganhou o mundo empresarial e hoje faz parte da estratégia de corporações como IBM, HP/Compaq, Sun e Fujitsu. 


\section{$2.2 \quad$ Usos}

A visão original do que vem a ser uma grade de computação estabelece uma metáfora entre a rede elétrica e a grade de computação. A rede elétrica disponibiliza energia elétrica sob demanda e esconde do usuário detalhes como a origem da energia e a complexidade da malha de transmissão e distribuição. Ou seja, se temos um equipamento elétrico, simplesmente o conectamos na tomada para que ele receba energia. A grade de computação, portanto, seria uma rede na qual o indivíduo se conecta para obter poder computacional (ciclos do processador, armazenamento, software, periféricos, etc). Portanto, pode-se ver grades de computação como uma nova plataforma para execução de aplicações.

Grande parte do interesse em grades de computação advém do potencial de atingir níveis de paralelismo inimagináveis em outras plataformas de execução de aplicações paralelas. Tais níveis de paralelismo podem se traduzir em tanto mais desempenho para aplicações existentes, quanto também a possibilidade de executar aplicações inteiramente novas, com gigantescos requisitos de computação e armazenamento. Além disso, a idéia de usar grades como laboratórios virtuais, que viabilizariam colaborações cientificas a distância é das mais animadoras.

A seguir, são dados dois cenários que se aplicam a grades [27].

- Cientistas de um determinado país desejam adquirir equipamentos para montar um laboratório de Física. Diversas universidades do país desejam tal laboratório, mas há dinheiro para apenas um. Utilizando grades de computação, seria possível que cientistas de universidades que não obtivessem o laboratório controlassem remotamente os instrumentos, podendo inclusive realizar experimentos à distância. São os chamados "colaboratórios" (Collaboratories), que permitem a colaboração entre indivíduos localizados em lugares geograficamente distantes.

- Diversas aplicações científicas (por exemplo, previsão do tempo, simulações mercadológicas, análise de prospecção de petróleo, reconhecimento de padrões, algoritmos de otimização) dependem de um grande poder computacional. Em muitos casos, estas aplicações podem paralelizar a sua computação de forma a se utilizar de praticamente todos os computadores disponíveis em determinada instituição. Muitas vezes a falta de poder computacional impede trabalhos e atrasa resultados. Por outro lado, freqüentemente é inviável a compra de computadores em nível suficiente para atender as necessidades de pico. Tal si- 
tuação torna-se ainda pior quando a necessidade de computação é esporádica, o que desencoraja a instituição a gastar dinheiro com algo que será usado poucas vezes. As grades podem resolver este problema, provendo acesso remoto a processadores de outras instituições que estejam ociosos naquele instante, por exemplo. No caso de grandes instituições com diversos departamentos, pode-se utilizar a grade para atender à maior necessidade computacional de um departamento através do compartilhamento do tempo ocioso das máquinas de outros departamentos.

\subsection{Aplicações Paralelas}

Devido a sua heterogeneidade, compartilhamento e complexidade, grades apresentam, em geral, maiores dificuldades para execução de aplicações paralelas. A adequação do uso de uma grade de computação depende em grande parte da aplicação a ser executada.

O que diferencia uma grade de um cluster, por exemplo? De maneira geral, podemos dizer que grades são mais distribuídas, diversas e complexas que outras plataformas. Aspectos que evidenciam esta distribuição, diversidade e complexidade são [26]:

- Heterogeneidade (dos componentes da grade),

- Alta dispersão geográfica (grades podem ter escala mundial),

- Compartilhamento (no sentido de que a grade não pode ser dedicada a uma aplicação),

- Múltiplos domínios administrativos (grades podem congregar recursos de várias instituições), e

- Controle distribuído (tipicamente não há uma única entidade que tenha poder sobre toda a grade).

Não há uma definição exata para grade. Uma plataforma para execução de aplicações paralelas que apresenta as características acima listadas certamente é uma grade. Mas a ausência de alguma das características não deve automaticamente desqualificar uma determinada plataforma como grade. 
Grades são mais complexas e dinâmicas que outras plataformas para execução de aplicações paralelas (por exemplo, clusters), e ainda falta muito a ser pesquisado. Há muito trabalho a ser feito na área de padronização, por exemplo, nos meios de interligação entre diferentes sistemas de grades. Felizmente, foi criado o Grid Forum [32] com o objetivo de viabilizar a discussão destes padrões, como também fomentar a área de grades de computação como um todo.

Quanto a aspectos técnicos propriamente ditos, há diversas questões em aberto na área. Em particular, acredita-se que é urgentemente necessário o progresso na criação de modelos de programação que melhor exponham a natureza da grade ao programador, e em melhores formas de lidar com grandes massas de dados na grade [26].

Segundo o que foi visto das características de uma grade, a comunicação na grade é um fator chave no projeto de aplicações paralelas. Ou seja, devido a alta dispersão geográfica comum em grades, é necessária uma boa estratégia para minimizar o tempo de comunicação, que é o tempo gasto para enviar e receber mensagens. O tempo de execução total tem que ser certamente inferior ao de uma versão

seqüencial da aplicação, caso contrário nem vale a pena paralelizar. É notório na literatura dos algoritmos paralelos distribuídos que se compararmos o tempo gasto de comunicação com o tempo total de execução do algoritmo, a redução dos custos de comunicação é uma das melhores formas de se obter aumento do desempenho dos algoritmos.

No próximo capítulo, será feita uma ligação entre essa necessidade de minimização do tempo de comunicação e arranjos sistólicos.

\subsection{O projeto IMPAR/InteGrade}

Esta seção visa dar uma visão geral do projeto IMPAR [37] (Infra-Estrutura de Middleware Para Aproveitamento de Recursos Ociosos em Sistemas Distribuídos), também conhecido como InteGrade [28]. O projeto refere-se a grade de computação que esta sendo elaborada pelo IME/USP. O orientador e o orientando deste trabalho são membros do projeto IMPAR, o orientador como coordenador e o orientando como aluno de mestrado, auxiliando na elaboração de programas teste para a grade, e de aplicações para a mesma.

O projeto IMPAR é uma arquitetura de middleware que permite a execução 
de uma ampla extensão de aplicações paralelas em um ambiente distribuído. Deste modo, é possível tirar proveito do poder computacional de várias organizações interligando computadores indepedentes e recursos de laboratórios sobre uma Intranet ou até mesmo a rede mundial (Internet).

Diferente de outras grades, o IMPAR é baseado em uma tecnologia moderna de middleware, utilizando o padrão CORBA [4] para sistemas de objetos distribuídos. Isso permite aproveitar funções já existentes, e assim diminuir o tempo com desenvolvimento e manutenção. As funções do InteGrade são exportadas como interfaces CORBA (CORBA IDL), sendo acessíveis por uma ampla variedade de linguagens de programação e sistemas operacionais.

Um importante requerimento do InteGrade é que os usuários que decidam compartilhar suas máquinas na grade não percebam nenhuma queda de rendimento nas suas aplicações. Isso é feito por um escalonador em nível de usuário. 


\section{Capítulo 3}

\section{Arranjos Sistólicos}

Há uma grande quantidade de literatura voltada para algoritmos sistólicos. Algumas boas referências sobre algoritmos sistólicos incluem [5, 7, 9, 11, 12, 16, 18]. Arranjos sistólicos são arquiteturas síncronas especiais consistindo de processadores ou células localmente e regularmente interconectadas. Os dados fluem através das células de modo que elas interagem a cada ciclo. Existe uma analogia com a biologia, onde a palavra sístole vem do ritmo de contração do coração para bombear sangue pelo corpo. Similarmente, arranjos sistólicos bombeiam dados seguindo um fluxo regular. As principais características de um algoritmo voltado para arranjos sistólicos são:

- Computação prossegue em frente de ondas.

- Leva em conta a entrada e a saída dos dados.

- Regularidade na disposição das células ou elementos de processamento e comunicação apenas com elementos vizinhos.

- Tem a vantagem de exigir comunicação com poucos vizinhos.

Devido principalmente a última característica (comunicação com poucos vizinhos), tais algoritmos podem se adequar ao uso em aglomerados. Porém, como os objetivos iniciais eram implementá-los com tecnologia VLSI (Very Large Scale Integration) de circuitos de alta densidade, tais algoritmos foram projetados para algoritmos de granularidade fina, o que prejudicaria a comunicação em uma grade, devido ao grande número de mensagens que seriam geradas na grade. Mas isso pode ser solucionado adaptando tais algoritmos para algoritmos de granularidade 
grossa, aumentado o tamanho das mensagens mas porém dimininuindo o número de mensagens. Foi isso o que fizemos no trabalho.

Outro fator importante é que esses algoritmos sistólicos se adequam bem no modelo SPMD (Single-Program Multiple-Data), onde o código a ser executado é igual para todos os processadores, diferenciando-se apenas os dados que cada processador recebe. Isso é importante porque assim a implementação pode ser feita utilizando bibliotecas de computação já existentes, como o MPI (Message Passing Interface), o BSP (Bulk Synchronous Parallel) e o PVM (Parallel Virtual Machine), que são as mais usadas. Ambas se adequam a algoritmos sistólicos, seguindo o modelo SPMD, pois nessas bibliotecas o mesmo código é executado em todas as máquinas. Ambas se adequam aos aglomerados, pois trabalham em ambientes heterogêneos. Neste trabalho será usado o MPI e o BSP.

Como exemplo, a Figura 3.1 ilustra o sistema sistólico de Weiser-Davis para multiplicação de matrizes. Tal sistema será explicado mais detalhadamente no próximo capítulo. Note a regularidade na disposição das células, e o número reduzido de vizinhos. As flechas indicam o sentido de fluxo dos dados, que devem ser vistos como se estivessem prosseguindo em uma frente de ondas. Nota-se também que as flechas indicam uma relação de dependência entre uma célula e todas aquelas que apontam para ela, ou seja, cada célula tem que esperar que todas as células que apontam para ela enviem seus dados, e só então realizar as computações necessárias, para então enviar os dados processados a seus vizinhos. No próximo capítulo essa relação de dependência será melhor estudada. 


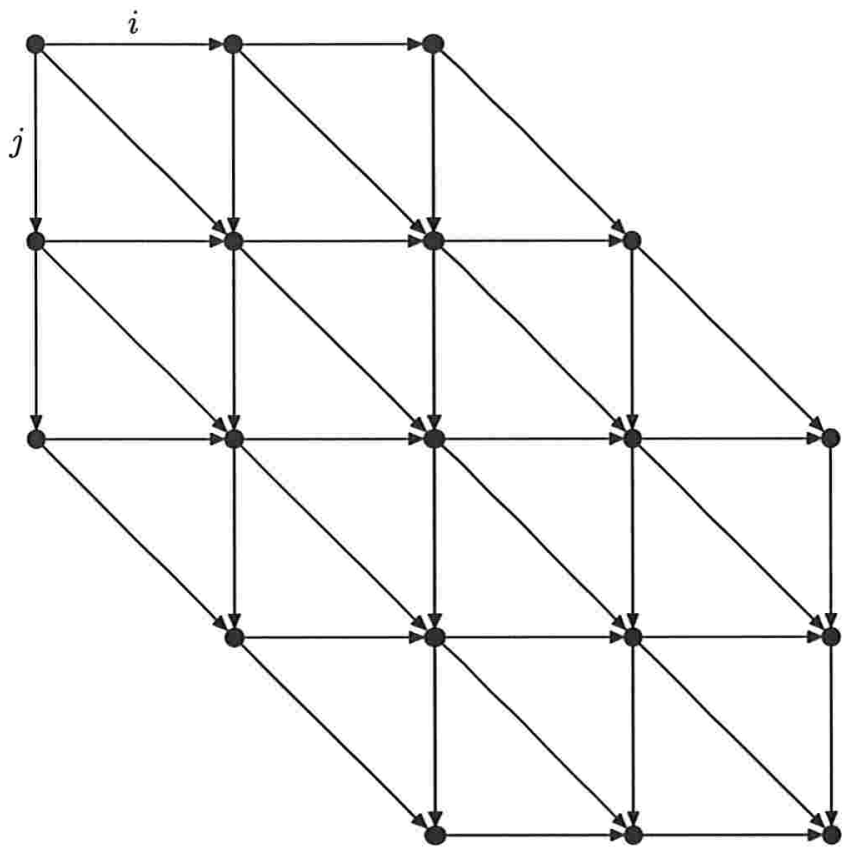

Figura 3.1: Sistema sistólico de Weiser Davis 


\section{Capítulo 4}

\section{Transformações de dependências}

Neste capítulo será estudado como projetar algoritmos paralelos a partir de laços aninhados. Este capítulo é portanto a base de todo trabalho, contendo várias definições, fórmulas e teoremas necessários para um melhor entendimento do método de transformação de dependências. Serão estudadas Equações de Recorrência Uniforme (ERU), grafo de dependências, função de tempo e função de alocação. Foram feitas várias figuras e exemplos ilustrativos a fim de ajudar a melhorar o entendimento, pois trata-se de uma parte mais teórica e complexa.

Este capítulo é baseado nos trabalhos de Song [29], Quinton e Robert [15, 16], cuja finalidade é produzir um arranjo sistólico de modo formal.

Um algoritmo contido dentro de um laço aninhado pode ser especificado por um sistema de equações de recorrência uniforme (ver definição 4.1.1), o qual associa cada instância (definida pelos índices dos laços) do algoritmo a um ponto de um domínio poliédrico convexo. Daqui em diante vamos chamar o algoritmo contido dentro de um laço aninhado apenas como algoritmo, e de instância do algoritmo como o estado do algoritmo em alguma das iterações do laço aninhado.

As computações envolvidas no algoritmo, bem como as dependências entre as instâncias do algoritmo, são transformadas por uma função de tempo e uma função de alocação. A função de tempo mapeia cada instância do algoritmo a um inteiro positivo que representará o tempo em que a mesma será executada; a função de alocação obtém a posição da célula que irá realizar a iteração no arranjo sistólico. 


\subsection{Equações de Recorrência Uniformes}

Seja $D$ o conjunto dos pontos com coordenadas inteiras pertencentes a um domínio poliédrico convexo de $R^{n}$, isto é,

$$
D=\left\{z \in Z^{n} \mid B z \leq b\right\}
$$

onde $B$ é uma matriz $m \times n$ e $b$ um vetor $m \times 1$ sobre $Z$.

Para um melhor entendimento dessas matrizes $B$ e $b$, é dado um exemplo mais adiante (exemplo 1).

Definição 4.1.1 Seja $D$ um domínio poliédrico convexo. Um sistema de equações de recorrência uniformes ERU é um sistema de m equações do tipo

$$
V_{i}(z)=f_{i}\left(V_{i_{1}}\left(z-\theta_{i_{1}}\right), \ldots, V_{i_{k}}\left(z-\theta_{i_{k}}\right)\right), 0 \leq i<m
$$

onde $z \in D, \theta_{i_{1}}, \ldots, \theta_{i_{k}}$ são vetores de $Z^{n}$.

Dizemos que um sistema desses computa as $m$ funções

$$
V_{0}, V_{1}, \ldots, V_{m-1}
$$

Vamos considerar também um caso simplificado, em que apenas $V_{0}$ interessa.

Definição 4.1.2 Um sistema de equações de recorrência uniformes ERU (simplificado) é o seguinte sistema de $m$ equações.

$$
\begin{aligned}
V_{0}(z) & =f\left(V_{0}\left(z-\theta_{0}\right), V_{1}\left(z-\theta_{1}\right), \ldots, V_{m-1}\left(z-\theta_{m-1}\right)\right), \\
V_{1}(z) & =V_{1}\left(z-\theta_{1}\right), \\
& \vdots \\
V_{m-1}(z) & =V_{m-1}\left(z-\theta_{m-1}\right),
\end{aligned}
$$

onde $z \in D$ e $\theta_{i}, 0 \leq i<m$, são vetores de $Z^{n}$. 
Definição 4.1.3 Seja $\Theta=\left\{\theta_{0}, \theta_{1}, \ldots, \theta_{m-1}\right\}$ o conjunto dos vetores $\theta_{i}$ de um sistema ERU. Os $\theta_{i}$ são ditos vetores de dependência do sistema.

Sejam os pontos $z, y \in D$, dizemos que $z$ é dependente de $y$, por $\theta_{i}$, se existe $\theta_{i} \in \Theta$, tal que

$$
z=y+\theta_{i}
$$

As dependências podem ser representadas por um grafo orientado chamado grafo de dependência do sistema ERU, denotado por $(D, \Theta)$. Os seus vértices são os pontos de $D$. Se o ponto $z$ é dependente de y por $\theta_{i}$, há uma aresta do vértice y ao vértice $z$. (Ver Figura 4.1.)

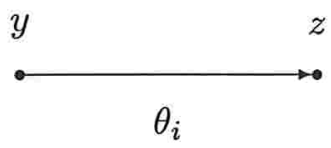

Figura 4.1: Ponto $z$ dependente de $y$

Se $z \in D$ e $z-\theta_{i} \notin D$, vamos chamar os valores $V_{i}\left(z-\theta_{i}\right), 0 \leq i<m$ de entradas do algoritmo, ou seja, os valores iniciais de um algoritmo. Os valores de $V_{i}(z)$ que apenas aparecem no lado esquerdo das equações correspondem às saídas do algoritmo. No caso de um algoritmo especificado por um sistema ERU simplificado, interessa-nos apenas a saída $V_{0}$, sendo as demais saídas meramente reproduções de entradas do algoritmo.

\section{Exemplo}

Exemplo $1 O$ algoritmo para multiplicar duas matrizes $N \times N, A=\left(a_{i j}\right)$ e $B=$ $\left(b_{i j}\right)$, produzindo a matriz produto $C=\left(c_{i j}\right), c_{i j}=\sum_{k=0}^{N-1} a_{i k} b_{k j}$, pode ser expresso pelo seguinte sistema ERU.

$$
\begin{aligned}
0 \leq i<N, & 0 \leq j<N, 0 \leq k<N, \\
C(i, j, k) & =C(i, j, k-1)+A(i, j-1, k) B(i-1, j, k) \\
A(i, j, k) & =A(i, j-1, k) \\
B(i, j, k) & =B(i-1, j, k)
\end{aligned}
$$


Os valores das entradas $A(i,-1, k)$ e $B(-1, j, k)$ são definidos como sendo os coeficientes $a_{i k}$ e $b_{k j}$, respectivamente. Os valores das entradas $\mathrm{C}(\mathrm{i}, \mathrm{j},-1)$ são iguais a 0 . Os valores das saídas $C(i, j, N-1)$, que aparecem apenas no lado esquerdo das equações, fornecem os resultados $c_{i j}$ da matriz produto.

Os vetores de dependência são

$$
\theta_{c}=\left(\begin{array}{l}
0 \\
0 \\
1
\end{array}\right), \theta_{a}=\left(\begin{array}{l}
0 \\
1 \\
0
\end{array}\right), \theta_{b}=\left(\begin{array}{l}
1 \\
0 \\
0
\end{array}\right)
$$

$D$ é o domínio poliédrico convexo definido por

$$
\left\{z \in Z^{3} \mid B z \leq b\right\}
$$

com

$$
B=\left(\begin{array}{rrr}
-1 & 0 & 0 \\
0 & -1 & 0 \\
0 & 0 & -1 \\
1 & 0 & 0 \\
0 & 1 & 0 \\
0 & 0 & 1
\end{array}\right), \quad b=\left(\begin{array}{c}
0 \\
0 \\
0 \\
N-1 \\
N-1 \\
N-1
\end{array}\right)
$$

A Figura 4.2 ilustra o grafo de dependências, com as dependências representadas por arestas orientadas, para $N=3$.

\subsection{Função de Tempo $\tau$}

Dado um sistema ERU, queremos obter uma função de tempo $\tau$ que escalona as computações associadas aos pontos do domínio $D$.

Para um dado $z \in D$, vamos supor que as computações $V_{i}(z)$ são realizadas em paralelo, levando uma unidade de tempo.

Para podermos efetuar as computações de $V_{i}(z)$, os seus argumentos necessários, naturalmente, devem ter sido computados antes. 


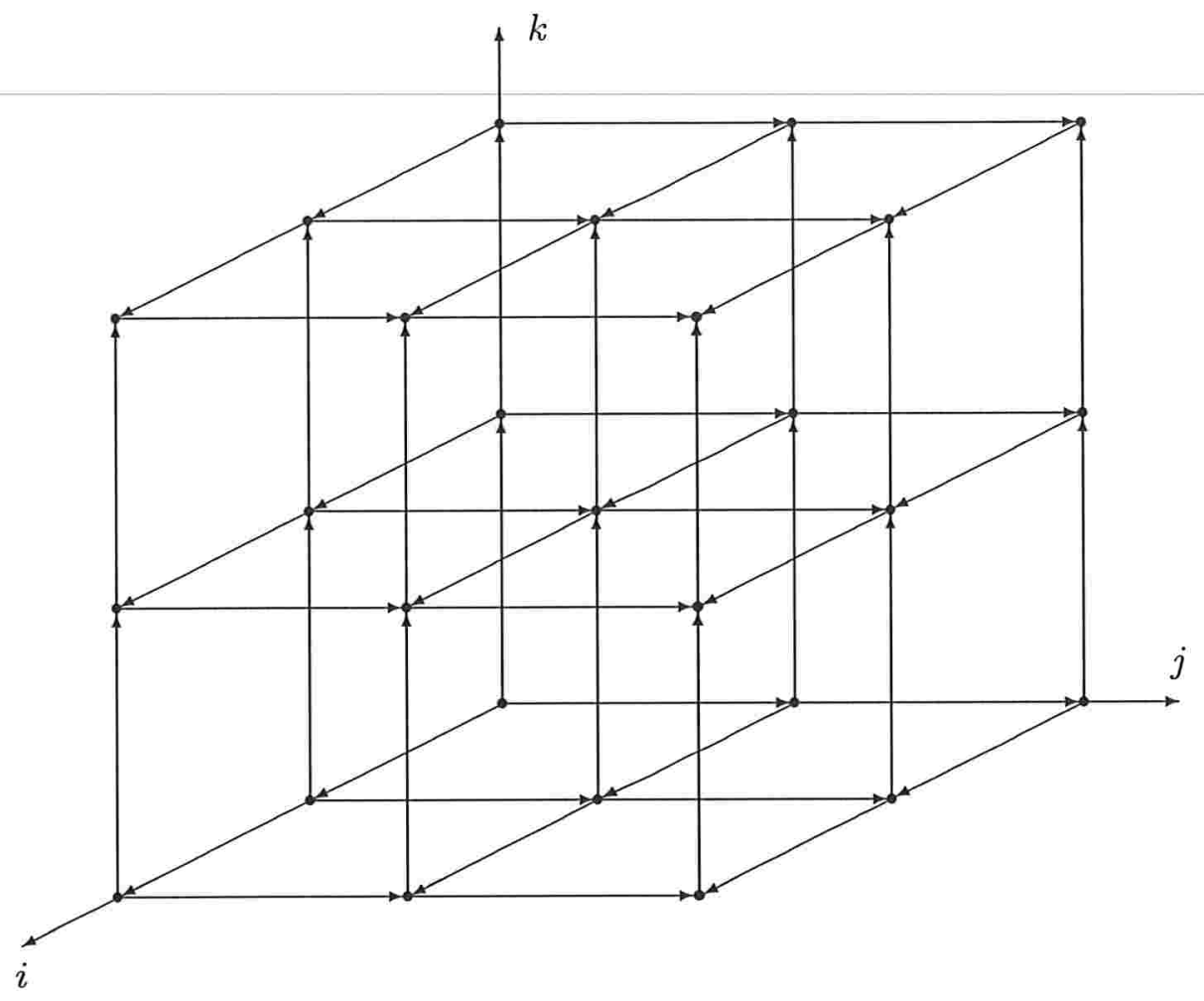

Figura 4.2: Grafo de dependências $(N=3)$

A função de tempo $\tau$ associa a cada ponto $z \in D$ o instante em que os valores de $V_{i}(z)$ são computados. Se tal função existir, então diremos que o sistema ERU é computável. Notamos informalmente que, para $V_{i}$ ser computável no ponto $z$, ela não deve depender dela mesma no próprio ponto $z$. Por exemplo, os seguintes dois sistemas ERU não são computáveis. Uma caracterização da computabiliade de sistemas ERU é dada por Karp, Miller e Winograd em [8].

$0 \leq i<N$

$$
U(i)=f(V(i-1), U(i))
$$

$0 \leq i<N$

$$
\begin{aligned}
& U(i)=g(V(i-2), W(i-1)) \\
& W(i)=h(U(i+1))
\end{aligned}
$$

Definição 4.2.1 Seja $x=\left(\begin{array}{c}x_{0} \\ x_{1} \\ \vdots \\ x_{n-1}\end{array}\right) \in D$. 
Sejam $\delta \in Z, \lambda=\left(\begin{array}{c}\lambda_{0} \\ \lambda_{1} \\ \vdots \\ \lambda_{n-1}\end{array}\right), \lambda_{i} \in Z$

A função de tempo $\tau: Z^{n} \rightarrow Z$ é a seguinte função linear

$$
\begin{aligned}
\tau(x) & =\lambda_{0} x_{0}+\lambda_{1} x_{1}+\ldots+\lambda_{n-1} x_{n-1}+\delta \\
& =\lambda^{T} x+\delta
\end{aligned}
$$

que satifaz as seguintes duas condições:

1. $\tau$ é não negativo sobre $D$.

2. Se $z$ depende de $y$, então $\tau(z)>\tau(y)$.

A primeira condição é por uma questão de conveniência. A segunda condição torna possível o escalonamento de computações dependentes.

Teorema 1 (Quinton e Robert [16])

Para um dado sistema ERU, com grafo de dependências $(D, \Theta)$ e com conjunto $V_{D}$ de vértices de $D$, os parâmetros $\lambda_{0}, \lambda_{1}, \ldots, \lambda_{n-1}$ e $\delta$ definem uma função de tempo $\tau$ se e somente se

1. $\forall v_{i} \in V_{D}, \quad \lambda^{T} v_{i}+\delta \geq 0 e$

2. $\forall \theta_{i} \in \Theta, \quad \lambda^{T} \theta_{i}>0$, ou seja, $\lambda^{T} \theta_{i} \geq 1$.

\section{Exemplo}

No exemplo 1 da página 19,

$$
\Theta=\left\{\theta_{c}=\left(\begin{array}{l}
0 \\
0 \\
1
\end{array}\right), \theta_{a}=\left(\begin{array}{l}
0 \\
1 \\
0
\end{array}\right), \theta_{b}=\left(\begin{array}{l}
1 \\
0 \\
0
\end{array}\right)\right\}
$$

Uma função de tempo $\tau(x)=\lambda_{0} x_{0}+\lambda_{1} x_{1}+\lambda_{2} x_{2}+\delta$ que satisfaz às condições do Teorema 1 deve satisfazer as seguintes restrições. 
Para a condição 1 , basta considerar o vértice $(0,0,0)$ :

$$
\delta \geq 0
$$

Para a condição 2, devemos ter

$$
\begin{aligned}
& \lambda_{0} \geq 1 \\
& \lambda_{1} \geq 1 \\
& \lambda_{2} \geq 1
\end{aligned}
$$

Assim podemos ter a seguinte função de tempo

$$
\tau(x)=x_{0}+x_{1}+x_{2} .
$$

\section{Interpretação do parâmetro $\lambda^{T} \theta_{i}$}

O Teorema 1 requer $\lambda^{T} \theta_{i} \geq 1$, para cada vetor de dependência $\theta_{i}$.

Seja $z$ dependente de $y$, por $\theta_{i}$, ou seja, $z=y+\theta_{i}$. Fazendo $\theta_{i}=z-y$ temos que

$$
\lambda^{T} \theta_{i}=\lambda^{T}(z-y)=\tau(z)-\tau(y)
$$

Assim, $\lambda^{T} \theta_{i}$ expressa a demora ou atraso entre a computação de $z$ e a computação de $y$. O Teorema 1 exige que tal demora seja maior ou igual a 1 .

\section{Funções de tempo ótimas}

O Teorema 1 dá as condições que permitem a obtenção de uma função de tempo. Uma pergunta natural que se faz é quando uma função de tempo é ótima. Vários critérios de optimalidade podem ser adotados.

Seja um sistema ERU, com grafo de dependências $(D, \Theta)$. Um critério é minimizar a demora entre computações dependentes segundo uma dependência $\theta_{k}$ de $\Theta$. Queremos assim

$$
\operatorname{minimizar} \lambda^{T} \theta_{k}
$$




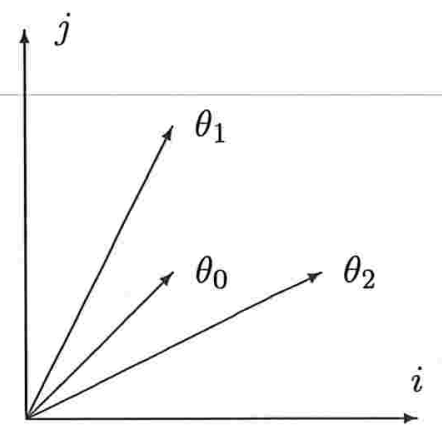

Figura 4.3: Vetores de dependência

sujeito a

$$
\lambda^{T} \theta_{i} \geq 1, \quad \forall \theta_{i} \in \Theta
$$

Exemplo 2 Seja o sistema ERU

$\begin{aligned} & 0 \leq i<13, \quad 0 \leq j<7 \\ & W(i, j)=f(W(i-1, j-1), W(i-1, j-2), W(i-2, j-1))\end{aligned}$

Temos os seguintes vetores de dependência, representados na Figura 4.3.

$$
\Theta=\left\{\theta_{0}=\left(\begin{array}{l}
1 \\
1
\end{array}\right), \theta_{1}=\left(\begin{array}{l}
1 \\
2
\end{array}\right), \theta_{2}=\left(\begin{array}{l}
2 \\
1
\end{array}\right)\right\}
$$

As condições impostas pelo Teorema 1 levam às seguintes restrições.

$$
\begin{aligned}
\lambda_{0}+\lambda_{1} & \geq 1, \\
\lambda_{0}+2 \lambda_{1} & \geq 1, \\
2 \lambda_{0}+\lambda_{1} & \geq 1, \\
\delta & \geq 1 .
\end{aligned}
$$

Minimizando a demora segundo a dependência

$$
\theta_{1}=\left(\begin{array}{l}
1 \\
2
\end{array}\right)
$$


ou seja, minimizando $\lambda_{0}+2 \lambda_{1}$, obtemos

$$
\begin{aligned}
\lambda_{0} & =1, \\
\lambda_{1} & =0, \\
\tau_{1}(x) & =x_{0} .
\end{aligned}
$$

Usando essa função de tempo $\tau_{1}$, o sistema ERU deste exemplo leva 12 unidades de tempo para ser computado.

Alternativamente, podemos minimizar a demora segunda a dependência

$$
\theta_{2}=\left(\begin{array}{l}
2 \\
1
\end{array}\right)
$$

obtendo como resultado

$$
\begin{aligned}
\lambda_{0} & =0, \\
\lambda_{1} & =1, \\
\tau_{2}(x) & =x_{1} .
\end{aligned}
$$

Usando a função de tempo $\tau_{2}$, o sistema ERU deste mesmo exemplo leva apenas 6 unidades de tempo para ser computado.

Ao invés de usar critérios locais, podemos também adotar um critério global, minimizando a maior diferença entre os tempos de computação dos pontos de $D$, ou seja,

$$
\text { minimizar } \max _{x, y \in D}|\tau(x)-\tau(y)|
$$

sujeito as restrições do Teorema 1.

Voltando ao exemplo 2, a maior diferença de tempos de computação ocorre nos pontos $x=(12,6)$ e $y=(0,0)$.

Ao minimizar $|\tau(x)-\tau(y)|=12 \lambda_{0}+6 \lambda_{1}$, obtemos

$$
\begin{gathered}
\lambda_{0}=0, \\
\lambda_{1}=1, \\
\tau_{3}(x)=\tau_{2}(x)=x_{1} .
\end{gathered}
$$




\subsection{Função de Alocação $\alpha$}

A função de tempo $\tau$ mapeia a cada ponto de $D$ o instante de tempo em que são realizadas as computações associadas ao ponto. Veremos nessa seção uma outra função, chamada função de alocação $\alpha: Z^{n} \rightarrow Z^{n-1}$, que mapeia cada ponto de $D$ a um ponto $\alpha(z)$ onde as computações associadas ao ponto $z$ são realizadas. O ponto $\alpha(z)$ pode ser interpretado como sendo a posição de um elemento de processamento de um sistema de computação.

Vamos supor que cada elemento de processamento é capaz de realizar as computações associadas a um ponto de $D$ em uma unidade de tempo.

A função de alocação $\alpha$ não deve mapear ao mesmo elemento de processamento, pontos diferentes de $D$ cujas computações são realizadas em um mesmo instante de tempo.

Definição 4.3.1 A função de alocação $\alpha: Z^{n} \rightarrow Z^{n-1}$ é uma função da forma

$$
\alpha(x)=\left(\alpha_{0}(x), \alpha_{1}(x), \ldots, \alpha_{n-2}(x)\right)
$$

onde cada $\alpha_{i}$ são funções lineares de $Z^{n}$ em $Z$, tais que

$$
\forall x, y \in D, \quad \alpha(x)=\alpha(y) \Rightarrow \tau(x) \neq \tau(y)
$$

\section{Hiperplanos de tempo}

Hiperplano de tempo é um hiperplano dos pontos $z \in D$ que possuem o mesmo valor de $\tau(z)$, ou seja, pontos cujas computações são executadas num mesmo instante. Ilustramos esse conceito através de um exemplo simples.

Exemplo 3 Considere o seguinte sistema ERU.

$$
\begin{aligned}
0 \leq i<4, \quad 0 \leq j<4 \\
U(i, j)=f(U(i, j-1), U(i-1, j))
\end{aligned}
$$

Temos

$$
\Theta=\left\{\theta_{0}=\left(\begin{array}{l}
0 \\
1
\end{array}\right), \theta_{1}=\left(\begin{array}{l}
1 \\
0
\end{array}\right)\right\}
$$




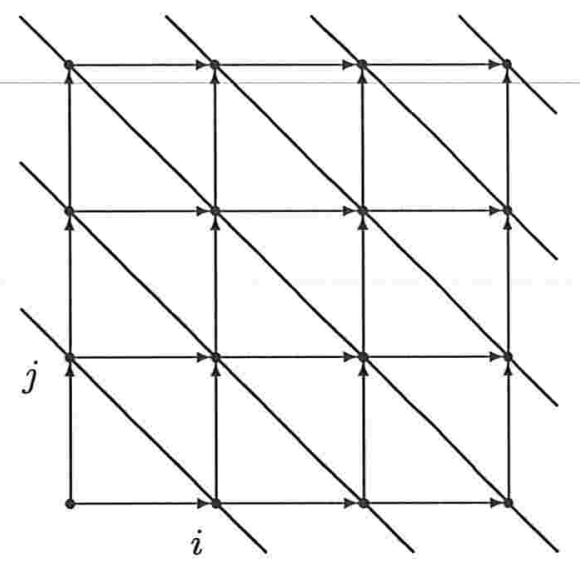

Figura 4.4: Hiperplanos de tempo

Seja a função de tempo $\tau(x)=x_{0}+x_{1}=i+j$, ou seja,

$$
\lambda=\left(\begin{array}{l}
1 \\
1
\end{array}\right) .
$$

Os hiperplanos de tempo são ortogonais a $\lambda$. Na Figura 4.4, os hiperplanos de tempo estão representados por linhas mais grossas.

No Teorema seguinte, vamos obter uma função de alocação $\alpha$ projetando o domínio $D$ segundo uma direção $u$, que não seja ortogonal a $\lambda$.

Teorema 2 (Quinton e Robert [16])

Seja u um vetor não nulo de $Z^{n}$ tal que $\lambda^{T} u \neq 0$.

Seja $u_{j} \neq 0$ um componente de $u$. A seguinte aplicação define uma função de alocação $\alpha(x)=\left(\alpha_{0}(x), \alpha_{1}(x), \ldots, \alpha_{n-2}(x)\right)$, onde

$$
\begin{array}{ll}
\alpha_{k}(x)=u_{j} x_{k}-u_{k} x_{j} & \text { se } 0 \leq k<j \\
\alpha_{k}(x)=u_{j} x_{k+1}-u_{k+1} x_{j} & \text { se } j \leq k<n-1 .
\end{array}
$$




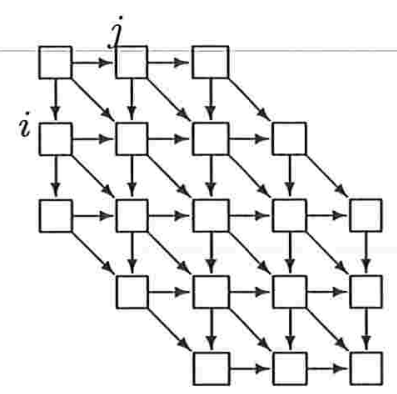

Figura 4.5: Sistema sistólico de Weiser-Davis

\section{Exemplos}

Vamos retomar o exemplo 1 da página 19, sobre a multiplicação de matrizes. Obtivemos

$$
\begin{gathered}
\lambda=\left(\begin{array}{l}
1 \\
1 \\
1
\end{array}\right) \\
\tau(x)=\lambda^{T} x=x_{0}+x_{1}+x_{2} .
\end{gathered}
$$

Vamos aplicar o Teorema 2, usando

$$
u=\left(\begin{array}{r}
-1 \\
-1 \\
1
\end{array}\right)
$$

Temos $\lambda^{T} u \neq 0$. Vamos escolher $u_{j}=u_{2}=1$. Temos

$$
\begin{aligned}
& \alpha_{0}(x)=u_{2} x_{0}-u_{0} x_{2}=x_{0}+x_{2} \\
& \alpha_{1}(x)=u_{2} x_{1}-u_{1} x_{2}=x_{1}+x_{2} .
\end{aligned}
$$

Portanto,

$$
\alpha(x)=S x=\left(\begin{array}{lll}
1 & 0 & 1 \\
0 & 1 & 1
\end{array}\right)\left(\begin{array}{l}
x_{0} \\
x_{1} \\
x_{2}
\end{array}\right)=\left(\begin{array}{l}
x_{0}+x_{2} \\
x_{1}+x_{2}
\end{array}\right) .
$$

Por meio desta função de alocação $\alpha$, os pontos de $D$ ficam mapeados aos elementos de processamentos com a disposição da Figura 4.5. 
A Figura 4.5 mostra um sistema de computação que realiza as computações do sistema ERU dado. A comunicação entre seus elementos de processamento é indicada pelas setas da figura. As direções de comunicação são obtidas pela aplicação da função $\alpha$ aos vetores de dependência do sistema. Assim,

$$
\begin{aligned}
& \alpha\left(\theta_{c}\right)=\left(\begin{array}{lll}
1 & 0 & 1 \\
0 & 1 & 1
\end{array}\right)\left(\begin{array}{l}
0 \\
0 \\
1
\end{array}\right)=\left(\begin{array}{l}
1 \\
1
\end{array}\right) \\
& \alpha\left(\theta_{a}\right)=\left(\begin{array}{lll}
1 & 0 & 1 \\
0 & 1 & 1
\end{array}\right)\left(\begin{array}{l}
0 \\
1 \\
0
\end{array}\right)=\left(\begin{array}{l}
0 \\
1
\end{array}\right) \\
& \alpha\left(\theta_{b}\right)=\left(\begin{array}{lll}
1 & 0 & 1 \\
0 & 1 & 1
\end{array}\right)\left(\begin{array}{l}
1 \\
0 \\
0
\end{array}\right)=\left(\begin{array}{l}
1 \\
0
\end{array}\right)
\end{aligned}
$$

É interessante observar que com essas funções de tempo e de alocação, acabamos de reproduzir o sistema sistólico para multiplicação de matrizes proposto por Weiser e Davis [22]. Mais ainda, se escolhermos

$$
u=\left(\begin{array}{l}
1 \\
1 \\
1
\end{array}\right)
$$

para projetar o domínio $D$, chegaremos à função de alocação

$$
\alpha(x)=S x=\left(\begin{array}{ccc}
1 & 0 & -1 \\
0 & 1 & -1
\end{array}\right)\left(\begin{array}{l}
x_{0} \\
x_{1} \\
x_{2}
\end{array}\right)=\left(\begin{array}{l}
x_{0}-x_{2} \\
x_{1}-x_{2}
\end{array}\right) .
$$

A Figura 4.6 mostra a disposição dos elementos de processamento obtida por essa nova função de alocação. Assim chegamos ao sistema sistólico proposto por Kung e Leiserson [10].

\section{Escolha da função de alocação}

Nessa seção vamos examinar a questão de funções de alocação ótimas . Os critérios de escolha são diversos. Um parâmetro usualmente considerado é o número de células ou elementos de processamento necessário. Os sistemas de computação obtidos por Weiser-Davis e Kung-Leiserson, por exemplo, necessitam de $3 N^{2}-3 N+1$ 


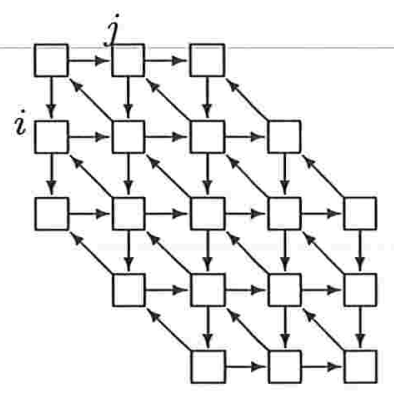

Figura 4.6: arranjo sistólico de Kung-Leiserson's para produto de matrizes.

células de processamento, para multiplicação de matrizes $N \times N$. Para implementação dos sistemas sistólicos obtidos em VLSI, o critério de minimizar o número de células é justificado pela necessidade e vantagem de obtenção de uma menor área de silício.

\section{Exemplos}

Voltando ao Exemplo 1 da página 19, sobre multiplicação de matrizes, desejamos obter uma função de alocação $\alpha$ tal que

$$
\begin{aligned}
& \alpha\left(\theta_{c}\right)=0 \text { ou } I_{s_{1}} \\
& \alpha\left(\theta_{a}\right)=0 \text { ou } I_{s_{2}} \\
& \alpha\left(\theta_{b}\right)=0 \text { ou } I_{s_{3}}, \quad \text { com } s_{1}, s_{2}, s_{3}=0 \text { ou } 1 .
\end{aligned}
$$

Seja $u=\left(\begin{array}{c}u_{o} \\ u_{1} \\ u_{2}\end{array}\right), \lambda^{T} u=u_{0}+u_{1}+u_{2}$.

Seja $u_{j}=u_{2} \neq 0$.

Temos

$$
\begin{aligned}
\alpha_{0}(x) & =u_{2} x_{0}-u_{0} x_{2} \\
\alpha_{1}(x) & =u_{2} x_{1}-u_{1} x_{2} \\
\alpha(x) & =\left(\begin{array}{ccc}
u_{2} & 0 & -u_{0} \\
0 & u_{2} & -u_{1}
\end{array}\right)\left(\begin{array}{l}
x_{0} \\
x_{1} \\
x_{2}
\end{array}\right) .
\end{aligned}
$$


Aplicando $\alpha$ aos vetores de dependência, temos

$$
\begin{aligned}
& \alpha\left(\theta_{c}\right)=\left(\begin{array}{ccc}
u_{2} & 0 & -u_{0} \\
0 & u_{2} & -u_{1}
\end{array}\right)\left(\begin{array}{l}
0 \\
0 \\
1
\end{array}\right)=\left(\begin{array}{l}
-u_{0} \\
-u_{1}
\end{array}\right) \\
& \alpha\left(\theta_{a}\right)=\left(\begin{array}{ccc}
u_{2} & 0 & -u_{0} \\
0 & u_{2} & -u_{1}
\end{array}\right)\left(\begin{array}{l}
0 \\
1 \\
0
\end{array}\right)=\left(\begin{array}{c}
0 \\
u_{2}
\end{array}\right) \\
& \alpha\left(\theta_{b}\right)=\left(\begin{array}{ccc}
u_{2} & 0 & -u_{0} \\
0 & u_{2} & -u_{1}
\end{array}\right)\left(\begin{array}{l}
1 \\
0 \\
0
\end{array}\right)=\left(\begin{array}{c}
u_{2} \\
0
\end{array}\right) .
\end{aligned}
$$

Uma solução possível é $u_{2}=1, u_{0}=u_{1}=0$, isto é

$$
u=\left(\begin{array}{l}
0 \\
0 \\
1
\end{array}\right)
$$

dando

$$
\alpha(x)=\left(\begin{array}{lll}
1 & 0 & 0 \\
0 & 1 & 0
\end{array}\right)\left(\begin{array}{l}
x_{0} \\
x_{1} \\
x_{2}
\end{array}\right)=\left(\begin{array}{l}
x_{0} \\
x_{1}
\end{array}\right)
$$

O sistema de computação assim obtido está mostrado na Figura 4.7 e corresponde uma solução conhecida na literatura proposta por, entre outros, Okuda e Song [13]. Um exemplo de uso desse arranjo sistólico está na Figura 4.8, que mostra a multiplicação de duas matrizes $A$ e $B$. Cada célula, representada pelos quadrados, recebe como entrada um elemento de $A$ e um elemento de $B$. Os valores são então acumulados a cada iteração, sendo que o valor inicial de cada célula é zero. Como resultado cada célula obterá o valor esperado de um elemento da matriz resultante $C=A \times B$, com os indices de linha e de coluna da matriz $C$ correspondendo aos da própria figura. Note que para multiplicar 2 matrizes $n \times n$ seriam necessários $n^{2}$ elementos de processamento.

Um algoritmo seqüencial trivial para multiplicar 2 matrizes $n \times n$ gasta $n^{3}$ iterações. O tempo total do algoritmo paralelo é a diferença de tempo entre a saida do último elemento $a_{n n}$ de $c_{n n}$ e a entrada do primeiro elemento $a_{11}$ em $c_{11}$. O elemento $a_{n 1}$ entra no arranjo sistólico somente após $n$ iterações, após isso espera-se $n-1$ iterações para que $a_{n n}$ entre no arranjo, e espera-se mais $n-1$ iterações para $a_{n n}$ chegar em $c_{n n}$. A algoritmo sistólico gasta portanto $3 n-2$ passos de computação, e o mesmo tanto para os passos de comunicação. Em termos de passos de computação, 


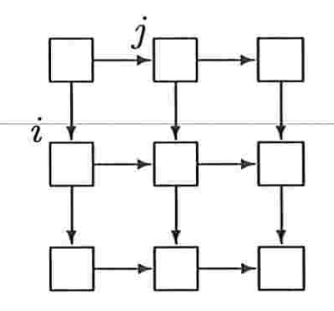

Figura 4.7: Um arranjo sistólico onde os valores de c permanecem no mesmo lugar.

obtém-se um speedup de $n^{3} /(3 n-2)$ ou $n^{2} / 3$ para $n$ grande o suficiente. Vendo a figura 4.8 nota-se que há elementos de processamento que nada fazem dependendo do instante, sendo que o máximo de elementos usados em um mesmo instante é 7 , no instante $t=4$. Este desperdicio de processamento é maior no começo e no fim do algoritmo, quando poucas células estão fazendo algo.

Freqüentemente precisamos obter não apenas um, mas vários produtos de matrizes. Deste modo o desperdício de processamento será menor quanto maior for o número de produtos de matrizes. Para $m$ produtos de 2 matrizes $n \times n$, seriam necessários $(m+1) n-1$ passos de computação e comunicação. Assim obtemos um speedup em termos de passos de computação de $\frac{m n^{3}}{(m+1) n-1}$ ou $n^{2}$ para $n$ e $m$ grandes o suficiente. Como estamos usando $n^{2}$ elementos de processamento, obtemos então um speedup linear. Em nossos experimentos, após fazer as adaptações necessárias para uma grade, obtivemos realmente um speedup linear, como será visto mais tarde. 

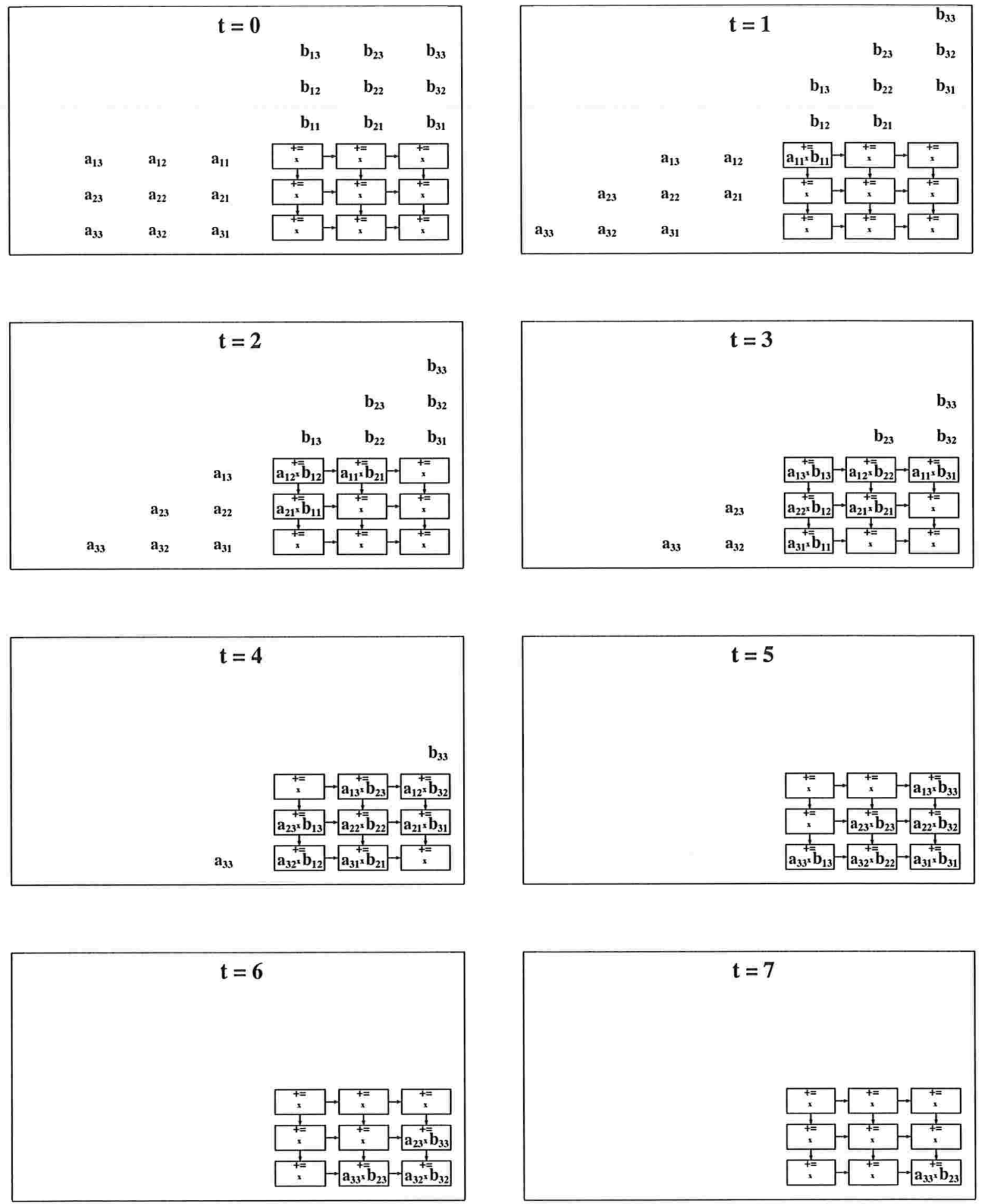

Figura 4.8: Multiplicação de Matrizes 


\section{Capítulo 5}

\section{Adaptando o Método para Aglomerados}

Neste capítulo será mostrado como adaptar o método descrito no capítulo 4 para uso em aglomerados. Abordaremos assuntos como a sincronização, granularidade, tolerância a falhas e heterogeneidade.

\subsection{Sincronização}

Arranjos sistólicos operam em modo síncrono. Como eles foram inicialmente projetados para serem implementados em pastilhas de silício, a sincronização pôde ser facilmente realizada. Em um aglomerado, porém, uma freqüente sincronização de todos os processadores seria muito custoso e portanto inviável. Felizmente, esse problema pode ser solucionado naturalmente em uma aglomerado usando envio de mensagens não bloqueante e recebimento de mensagens bloqueante, evitando primitivas explicitas de sincronização. No caso das nossas implementações dos algoritmos sistólicos, as únicas sincronizações ocorrem para medir os tempos, e ocorrem na parte final do programa, após os trechos relativos ao algoritmo em si. Desta forma isto não atrapalha a medição dos tempos.

Como estamos usando o modelo SPMD para os algorimos paralelos, a biblioteca MPI (Message Passing Interface) se adequa perfeitamente, assim como a biblioteca BSP (Bulk Synchronous Parallel). No caso da biblioteca MPI, a função MPI_Send para envio de mensagens é considerada bloqueante, pois ela é não bloqueante apenas para mensagens até um certo tamanho, que é definido pela capacidade do buffer de 
mensagens. Para mensagens cujo tamanho ultrapasse o buffer, ela bloqueia até que o processo destinatário receba totalmente a mensagem. O problema disso é que no modelo sistólico todos os processos agem sincronizadamente, ou seja, todos os processos enviam a mensagem ao mesmo tempo. Assim, para mensagens com tamanho acima do buffer, se todos os processos tiverem que enviar dados para um outro processo, haveria um deadlock, pois todos ficariam bloqueados. Note que se todos os processos enviam uma mensagem ao mesmo tempo, nenhum processo estará recebendo mensagens. Isto pode ser solucionado usando-se a função MPI_ISend, que não é bloqueante para qualquer tamanho de mensagem. Deste modo, em algum instante as mensagens seriam recebidas pelos processos destinatários. Porém, para evitar problemas de sobreposição de dados escrevendo em um área de memória que ainda esteja sendo enviada, necessita-se de mecanismos de confirmação de finalização da mensagem, para então reutilizar a área de memória usada no armazenamento da mensagem. Tais mecanismos de confirmação aumentam o número de mensagens no aglomerado, aumentando o problema da latência e também a complexidade e manutenção das aplicações.

Para evitar o uso de mecanismos de confirmação, ou seja, utilizar o MPI_Send bloqueante, optou-se por uma ligeira modificação do modelo sistólico. A modificação consiste no escalonamento entre os envios e recebimentos de mensagens, de forma a emparelhar os envios com os recebimentos de mensagens. Desta forma, no instante em que um processo envia uma mensagem, o processo destinatário estará recebendo a mensagem em um buffer previamente alocado, e vice-versa, evitando-se assim o problema do deadlock e também o aumento no número de mensagens causado pelos mecanismos de confirmação.

No caso do BSP não foi necessário nenhuma modificação do modelo sistólico, pois o BSP é implementado de forma a não ocorrer os deadlocks descritos anteriormente. O BSP utilizado nas nossas implementações segue o modelo do BSP de Oxford [53].

\subsection{Granularidade}

Considere agora um aspecto observado no exemplo de multiplicação de matrizes do capítulo anterior. Cada célula realiza muito poucas instruções em cada passo de computação, ou seja, apenas uma multiplicação e uma adição. Esta granularidade fina não é apropriada para aglomerados, devido a disparidade de velocidade 
entre comunicação e computação. Na grade, a comunicação seria prejudicada principalmente devido a latência da comunicação, que demoraria muito mais do que a computação. Para solucionar este problema, é necessário adaptar a granularidade fina dos algoritmos sistólicos para granularidade grossa, a fim de fazer o tempo de computação prevalecer sobre o tempo de comunicação.

No exemplo de multiplicação de matrizes, isto pode ser realizado considerando cada elemento de entrada do arranjo sistólico como uma submatriz. Ou seja, ao invés de cada célula receber um simples elemento de cada matriz $A$ e $B$, receber uma submatriz de $A$ e de $B$. Dentro de cada célula, computar-se-ia a multiplicação das duas submatrizes de $A$ e de $B$. Isto diminuiria substancialmente o número de comunicações, e portanto a latência, e também aumentaria proporcionalmente o tempo de computação sobre o tempo de comunicação. Porém, deve-se tomar cuidado para não criar submatrizes muito grandes, ao ponto de ser necessário fazer swap. Isto prejudicaria tanto o tempo de computação como o tempo de comunicação. Ilustramos isto na figura 5.1 onde, por simplicidade, mostramos submatrizes de tamanho $2 \times 2$. É claro que este tamanho pode ser ajustado para obter melhor desempenho ou simplesmente para fazer testes.

Pode ser feita uma análise de complexidade similar ao que foi feito no capítulo anterior para o algoritmo de multiplicação de matrizes. Ao invés de simples elementos, agora consideramos submatrizes. Considere a multiplicação de duas matrizes $n \times n$ e um arranjo sistólico de $p \times p$ elementos de processamento, assumindo que $n$ é divisível por $p$. Projetando a matriz sobre o arranjo sistólico, cada matriz pode ser vista como uma matriz $p \times p$ cujos elementos são submatrizes $n / p \times n / p$.

Como no caso anterior, o algoritmo requer um total de $3 p-2$ passos de computação, e o mesmo tanto de passos comunicação. Neste caso um passo de computação envolve o produto e a soma de duas submatrizes, e o passo de comunicação envolve o envio e o recebimento de submatrizes. O algoritmo seqüencial, como no caso anterior, requereria $p^{3}$ passos de computação. Portanto obteríamos um speedup em termos de passos de computação de $p^{3} /(3 p-2)$, ou $p^{2} / 3$ aproximadamente.

Novamente suponha que precisamos realizar $m$ produtos de 2 matrizes, em pipeline, ao invés de apenas um (ver figura 5.2). Precisaremos de um total de $(m+2) p-2$ passos de computação e comunicação. O speedup em termos de passos de computação é $\frac{m p^{3}}{(m+2) p-2}$ ou aproximadamente $p^{2}$ para $m$ suficientemente grande. Como antes, pelo fato de estarmos usando $p^{2}$ elementos de processamento, obtemos speedup linear. 


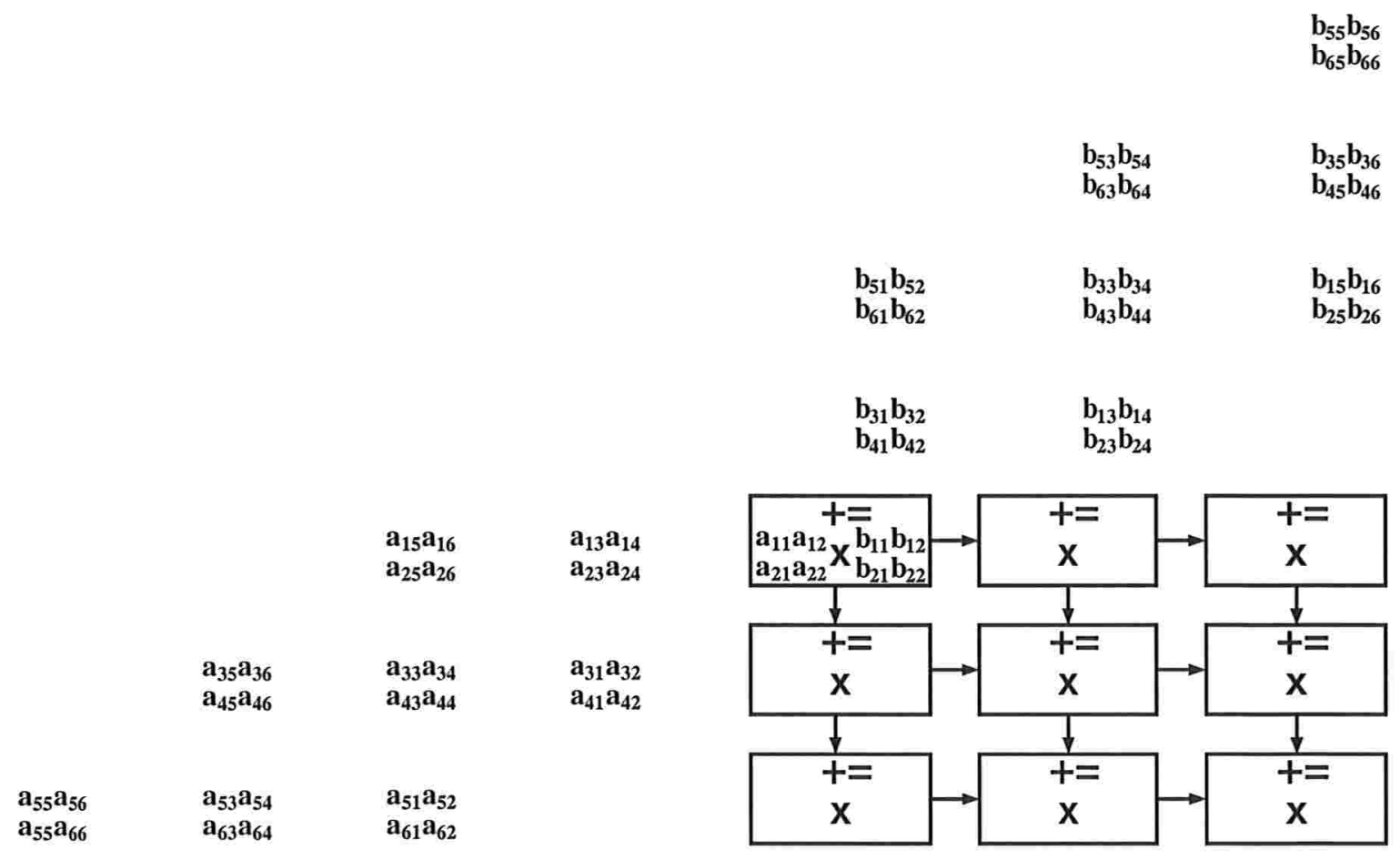

Figura 5.1: Aumento da Granularidade 


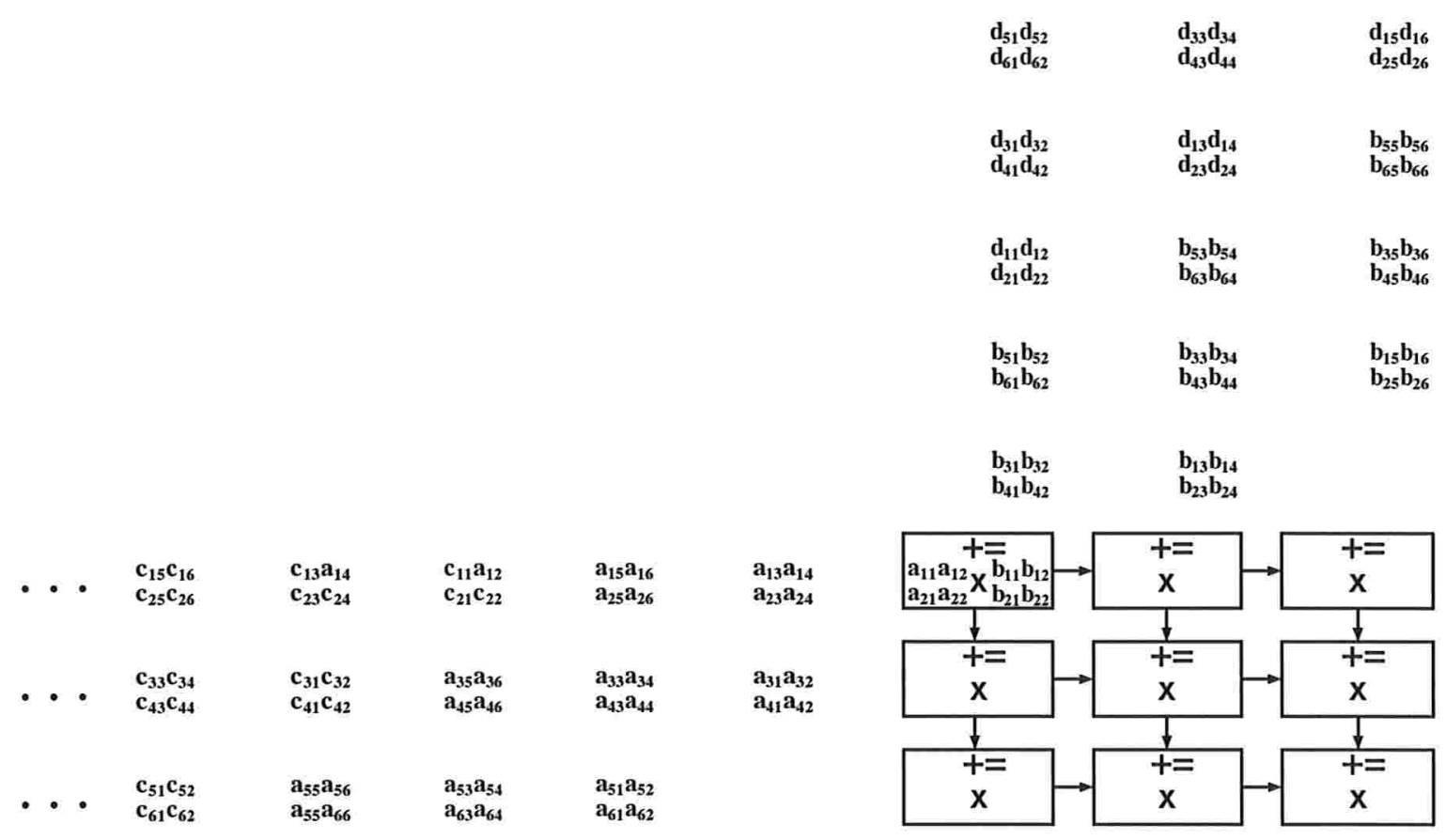

Figura 5.2: Aumento da Granularidade e Uso de Pipeline 
Na subseção a seguir será destacado um exemplo de uso de nossa multiplicação de matrizes usando pipeline e aumento de granularidade. O exemplo descreve sucintamente as Trasnformadas de Legendre, que podem se beneficiar da multiplicação de matrizes mostrada nesta seção.

\subsubsection{Transformadas de Legendre}

No modelo de circulação atmosférica global usada para previsão de tempo, são usadas as computações das Transformadas de Fourier e Legendre [2, 3].

Um modelo global simula o comportamento dos campos atmosféricos ao longo do tempo. Equações diferenciais parciais são resolvidas em dois espaços: o espaço da grade (aqui usamos o termo grade no sentido matemático) e o espaço do espectro. A Transformada de Fourier move um campo entre as representações da grade e a de Fourier, enquanto que a Transformada de Legendre move um campo entre as representações de Fourier e a do espectro.

As Transformadas de Fourier são computadas usando o bem conhecido FFT (Fast Fourier Transform). As Trasnformadas de Legendre constituem a parte mais consumidora de tempo e podem ser computadas como múltiplas multiplicações de matrizes para tirar total vantagem de hardwares vetoriais.

No capítulo 7 mostraremos que múltiplos produtos de matrizes podem ser computados eficientemente em um aglomerado, utilizando o algoritmo sistólico adaptado que foi mencionado anteriormente. Portanto, nosso algoritmo paralelo pode ser usado para computar as Trasnformadas de Legendre no modelo de circulação atmosférica global.

Enfatizamos as simultâneas multiplicações de matrizes em forma de pipeline usada no nosso algoritmo. Isso é muito relevante neste caso onde temos mais matrizes para serem multiplicadas do que o número de processadores. Note que nossa proposta tem um desempenho melhor do que propostas do tipo processor-farm ou bag-of-tasks, onde cada processador livre requisita e obtém um par de matrizes para serem multiplicadas.

\subsection{Tolerância a Falhas}

Este assunto não foi implementado neste trabalho, mas discutiremos o assunto. 
Tolerância a falhas refere-se a capacidade de lidar com um certo número de falhas aleatórias e ao mesmo tempo manter robustez e confiabilidade [34]. Como exemplo de robustez, se uma das máquinas do aglomerado cai ou se torna inacessível, não podemos perder toda a computação realizada nas outras máquinas. Deve-se criar um meio de prosseguir as computações sem ter que recomeçar tudo de novo. A confiabilidade fica mais voltada para a parte de hardware, através da verificação da paridade, principalmente. Também existem formas algorítmicas de confiabilidade. No caso de matrizes cria-se mais uma linha e mais uma coluna para armazenarem a soma da linha e da coluna, respectivamente. Seria algo equivalente ao método da paridade.

A solução usada em arranjos sistólicos, que eram implementados em circuitos VLSI, era projetar pastilhas de silício com circuitos redundantes que permitissem células (elementos de processamento) defeituosas serem transpassadas quando ocorresse uma falha, e assim continuar o processamento na próxima célula que não estivesse defeituosa. A célula defeituosa passaria a funcionar apenas para repassar dados, sem realizar computações.

Em aglomerados, assim como em praticamente todos os sistemas paralelos e distribuídos, tal idéia de redundância também é usada. No caso de grades, porém, são necessários certos cuidados adicionais devido à maior complexidade envolvida, e maior instabilidade dos componentes que formam a grade. Deve-se ter em mente que em uma grade os componentes que a formam não são dedicados, podendo interromper suas atividades a qualquer instante.

A idéia de redundância consiste em distribuir cada parte do processamento para um conjunto de computadores, e assim ter cada membro do conjunto executando exatamente as mesmas computações, e assim garantir maiores chances de que pelo menos um dos elementos do conjunto consiga terminar.

Além da redundância de processamento, aglomerados podem oferecer também a redundância de dados que sejam importantes, evitando-se o risco de perder dados importantes que estejam em uma única máquina. Isso já é usado na Internet, por exemplo, no caso dos servidores de endereços e de páginas.

\subsection{Heterogeneidade de Hardware}

Este assunto não foi implementado neste trabalho, mas discutiremos o assunto. 
Dentro de um aglomerado é comum encontrarmos diferentes configurações entre os componentes que o compõe. Tal fato deve-se as constantes atualizações de hardware no mercado, aumentando a disparidade de poder de processamento entre as máquinas existentes. No caso de grades, a situação torna-se mais grave devido a sua maior abrangência. Deste modo, o desempenho de uma aplicação seguindo o modelo sistólico seria ditado pelo elemento de menor poder de processamento. Porém, isso resultaria no aumento do tempo ocioso das demais máquinas, ocasionando desperdício de recursos.

Uma das formas de se minimizar o tempo ocioso baseia-se na sobreposição de comunicação e computação, que consiste em atribuir novas tarefas para um processo que estivesse esperando a finalização de uma comunicação. Porém, isso é bastante de se conseguir na prática, e não é importante no caso da grade se supormos que haverá abundância de recursos. O mais importante seria obter mais agilidade na resposta, não importanto tanto se haverá desperdício de recursos.

A solução que foi pensada para o trabalho consiste no uso de redundância, portanto a mesma solução que foi pensada para tolerância a falhas. Um conjunto de processos receberia a mesma tarefa, e esperaria-se pelo primeiro que terminasse e enviasse a tarefa para os processos seguintes. Para a implementação do recebimento da mensagem, pensou-se no uso de funções de recebimento de mensagens do tipo receive_any, que podem receber uma mensagem de qualquer processo, portanto de qualquer processo em um conjunto de processos. Porém, ficaram dúvidas sobre como ficariam as funções de envio de mensagem, pois as funções de envio de mensagem exigem um destinatário fixo. Também ficaram dúvidas se deveria haver um processador central coordenando o envio e recebimento de mensagens para solucionar a questão anterior, mas isso descaracterizaria o modelo sistólico de descentralização, e enfraqueceria o conceito de tolerância a falhas, pois o processador central não poderia falhar. 


\section{Capítulo 6}

\section{Similaridade}

Definiremos neste capítulo o problema de similaridade e em seguida mostraremos como paralelizá-lo [49]. Seja $A=a_{1} a_{2} \ldots a_{m}$ e $C=c_{1} c_{2} \ldots c_{n}$ duas palavras sobre um alfabeto $I$.

\begin{tabular}{|c|c|c|c|c|c|c|c|c|c|c|c|c|c|c|c|c|c|c|}
\hline$A$ & $\mathrm{a}$ & & $t$ & $\mathrm{t}$ & C & a & - & $t$ & & $A$ & $a$ & C & $\mathrm{t}$ & $\mathrm{t}$ & $\mathrm{c}$ & $\mathrm{a}$ & - & $t$ \\
\hline$C$ & $\mathrm{a}$ & $\mathrm{t}$ & $t$ & C & - & $\mathrm{a}$ & c & $\mathrm{g}$ & & $C$ & $\mathrm{a}$ & - & $\mathrm{t}$ & $\mathrm{t}$ & $\mathrm{c}$ & $\mathrm{a}$ & $\mathrm{c}$ & $\mathrm{g}$ \\
\hline Score & 1 & 0 & 1 & 0 & 0 & 1 & 0 & 0 & 3 & Score & 1 & 0 & 1 & 1 & 1 & 1 & 0 & 0 \\
\hline
\end{tabular}

Figura 6.1: Exemplos de alinhamento

Para alinhar duas palavras, inserimos espaços nas duas seqüencias de tal modo que elas se tornam iguais em comprimento. Note a figura 6.1 onde cada coluna consiste de um simbolo de $A$ (ou espaço) e um símbolo de $C$ (ou espaço). Um alinhamento entre $A$ e $C$ é um emparelhamento dos símbolos $a \in A$ e $c \in C$ de tal modo que se desenharmos linhas entre os simbolos que combinam, essas linhas não podem cruzar umas as outras. O alinhamento mostra a similaridade entre duas palavras. Mais especificamente, estamos falando sobre cadeias de DNA, que podem ser pensadas como palavras. A figura 6.1 mostra dois simples alinhamentos onde associamos um score de 1 quando os simbolos em uma coluna combinam, e zero caso contrário. O alinhamento à direita tem um maior score (5) do que o da esquerda (3).

Uma forma mais geral de atribuir scores é feito como segue. Cada coluna do alinhamento recebe um certo valor dependendo do seu conteúdo e o score total para o alinhamento é a soma dos valores atribuídos a suas colunas. Considere uma coluna consistindo de símbolos $r$ e $s$. Se $r=s$ (ou seja, combinam), será recebido um valor $p(r, s)>0$. Se $r \neq s$ (não combinam), a coluna receberá um 
valor $p(r, s)<0$. Finalmente, uma coluna com um espaço recebe um valor $-k$, onde $k \in N$. Procuramos pelo alinhamento (alinhamento ótimo) que de o máximo score. Este máximo score é chamado de similaridade entre as duas palavras e denotado por $\operatorname{sim}(A, C)$ para duas palavras $A$ e $C$. Pode haver mais de um alinhamento com máximo score.

Considere $|A|=m$ e $|C|=n$. Há $m+1$ possíveis prefixos de $A$ e $n+1$ prefixos de $C$. Assim, podemos arranjar nossos cálculos em uma matriz $S(m+1) \times(n+1)$ onde cada $S(r, s)$ representa a similaridade entre $A[1 . . r]$ and $C[1 . . s]$, que denotam prefixos $a_{1} a_{2} \ldots a_{r}$ e $c_{1} c_{2} \ldots c_{s}$, respectivamente.

Observe que podemos computar os valores de $S(r, s)$ usando três valores prévios $S(r-1, s), S(r-1, s-1)$ e $S(r, s-1)$, pois há apenas três modos de computar um alinhamento entre $A[1 \ldots r]$ e $C[1 \ldots s]$. Podemos alinhar $A[1 . . r]$ com $C[1 . . s-1]$ e alinhar um espaço com $C[s]$, ou alinhar $A[1 . . r-1]$ com $C[1 . . s-1]$ e combinar $A[r]$ com $B[s]$, ou alinhar $A[1 . . r-1]$ com $C[1 . . s]$ e alinhar um espaço com $A[r]$.

A matriz de similaridade $S$ do alinhamento entre as palavras $A$ e $C$ pode ser computada da seguinte maneira:

$$
S(r, s)=\max \left\{\begin{array}{l}
S[r, s-1]-k \\
S[r-1, s-1]+p(r, s) \\
S[r-1, s]-k
\end{array}\right.
$$

Na figura 6.2 são mostradas as dependências entre as computações para $A=$ baabcbca e $B=$ baabcabcab.

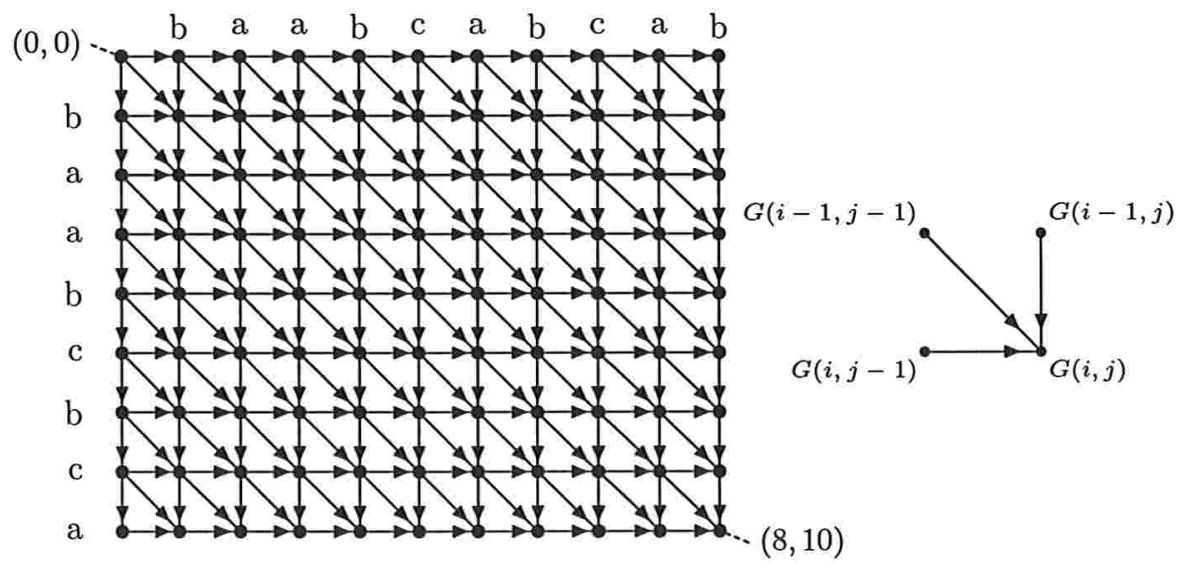

Figura 6.2: Vetores de dependência para $A=$ baabcbca e $B=$ baabcabcab.

É fácil notar que em um algorimo seqüencial isso seria facilmente feito em um laço aninhado. O algorimo sistólico ficaria então parecido com o de multiplicação 
de matrizes, com a vantagem de que agora seria necessário apenas um vetor de elementos de processamento, e não mais uma matriz. Em uma grade por exemplo, a palavra $A$ pode ser lida pedaço a pedaço por cada elemento de processamento com cada pedaço sendo lido em diferentes tempos para cada processador. Um esquema de como ficam estes processadores na grade pode ser visto na figura 6.3.

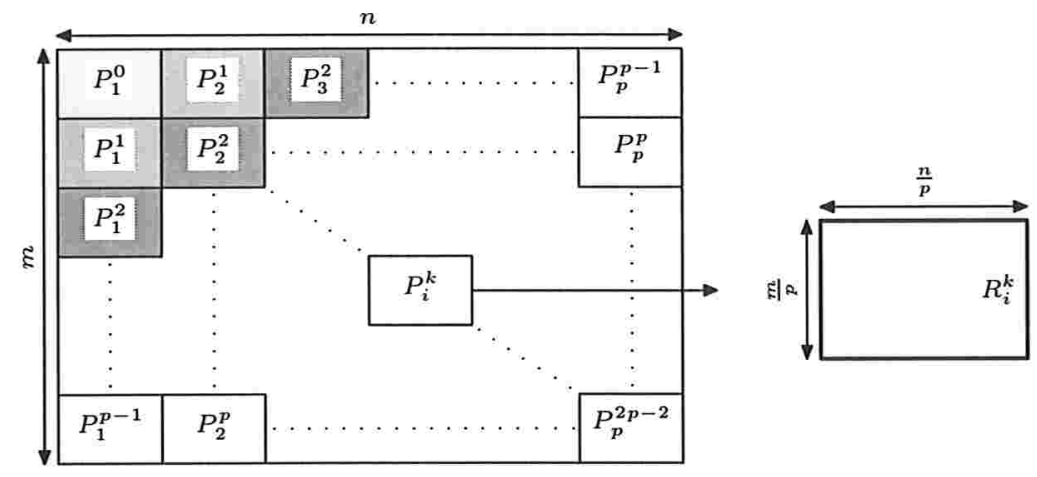

Figura 6.3: Algoritmo sistólico de similaridade ou alinhamento de cadeias

A notação $P_{i}^{k}$ denota o trabalho do processador $P_{i}$ no passo de computação $k$. Portanto inicialmente $P_{1}$ começa computando no passo de computação 0. Depóis, $P_{1}$ e $P_{2}$ podem trabalhar no passo de computação $1, P_{1}, P_{2}$ e $P_{3}$ no passo de computação 2, e assim em diante. 


\section{Capítulo 7}

\section{Resultados experimentais}

Nossos experimentos foram executados em um cluster do tipo Beowulf e também em uma grade de desktops.

No Beowulf, de 16 nós, os algoritmos foram implementados usando o padrão ANSI C, usando o LAM/MPI 6.5.8 [52]. O sistema operacional foi o Debian Linux 2.2.19. Cada nó tem um processador AMD Athlon Thunderbird de $1.2 \mathrm{GHz}, 256 \mathrm{~KB}$ de cache L2, $768 \mathrm{MB}$ de memória RAM e $30.73 \mathrm{~GB}$ de disco rígido. Os 16 nós estão conectados por um Switch 3COM 3300 FastEthernet 100Mb.

$\mathrm{Na}$ grade de desktops, no total de 18 desktops, os algoritmos também foram implementados usando o padrão ANSI C, usando o LAM/MPI 7.1.1 [52] e uma implementação da interface BSP de Oxford [53] para o InteGrade [28]. O InteGrade foi descrito na seção 2.4. Os 18 desktops foram obtidos pela junção das redes Eclipse [51] e LCPD [50](Laboratório de Computação Paralela e Distribuída). A rede Eclipse é uma rede de 16 desktops interconectados em uma rede local via Ethernet $100 \mathrm{Mb}$, dos quais foram utilizados 11 nós Athlon XP 1700+, de 1492,9 Mhz, 256 KB de cache e 512 MB de RAM. A rede LCPD é uma rede de 9 desktops interconectados em uma rede local via Ethernet $100 \mathrm{Mb}$, dos quais foram utilizados 7 desktops, consistindo de 4 pentium II $400 \mathrm{Mhz}, 512 \mathrm{~KB}$ de cache, $256 \mathrm{MB}$ de RAM e de 3 Athlon XP $1700+$, de 1492,9Mhz, $256 \mathrm{~KB}$ de cache e $512 \mathrm{MB}$ de RAM.

A seguir serão apresentados os tempos e speedups para a implementação do algoritmo multiplicação de matrizes e o algoritmo de similaridade ou alinhamento de cadeias descritos anteriormente. 


\subsection{Multiplicação de Matrizes}

A algoritmo de multiplicação de matrizes descrito nos capítulos 4 e 5 foi implementado usando tanto os modelos MPI (Message Passing Interface) como o BSP (Bulk Synchronous Parallel). A seguir, serão mostrados os tempos e os speedups para as implementações no Beowulf e depois para a grade de desktops usando o InteGrade e o MPI.

\subsubsection{No Beowulf}

As figuras 7.1 e 7.2 mostram as curvas de tempo e speedup para 50 produtos, em pipeline, de duas matrizes de tamanho $180 \times 180$ a $300 \times 300$. Note que para estes experimentos os speedups aumentam com o tamanho da matriz.

As figuras 7.3 e 7.4 mostram as curvas de tempo e speedup para 50 produtos, em pipeline, de duas matrizes de tamanho $420 \times 420$ a $900 \times 900$. Aqui observamos o comportamento superlinear das curvas de speedup.

As figuras 7.5 e 7.6 mostram os tempos de processamento e speedups para 50 produtos, em pipeline, de duas matrizes de tamanho $900 \times 900$ a $1800 \times 1800$. Note que aqui os speedups começam a decair quanto maior o tamanho da matriz, $\mathrm{e}$ portanto quanto maior o tamanho das mensagens. 


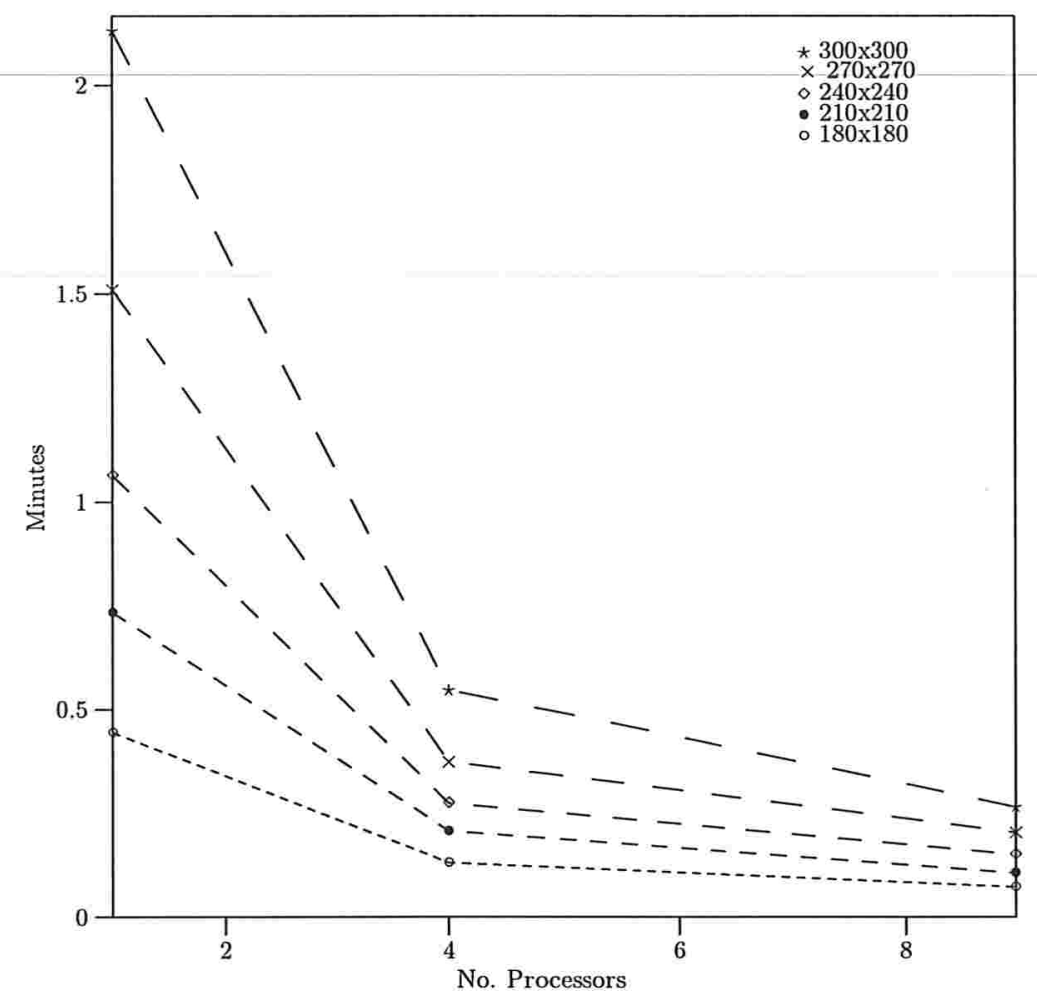

Figura 7.1: Tempo de Processamento para Matrizes de Tamanho $180 \times 180$ a 300 $\times 300$.

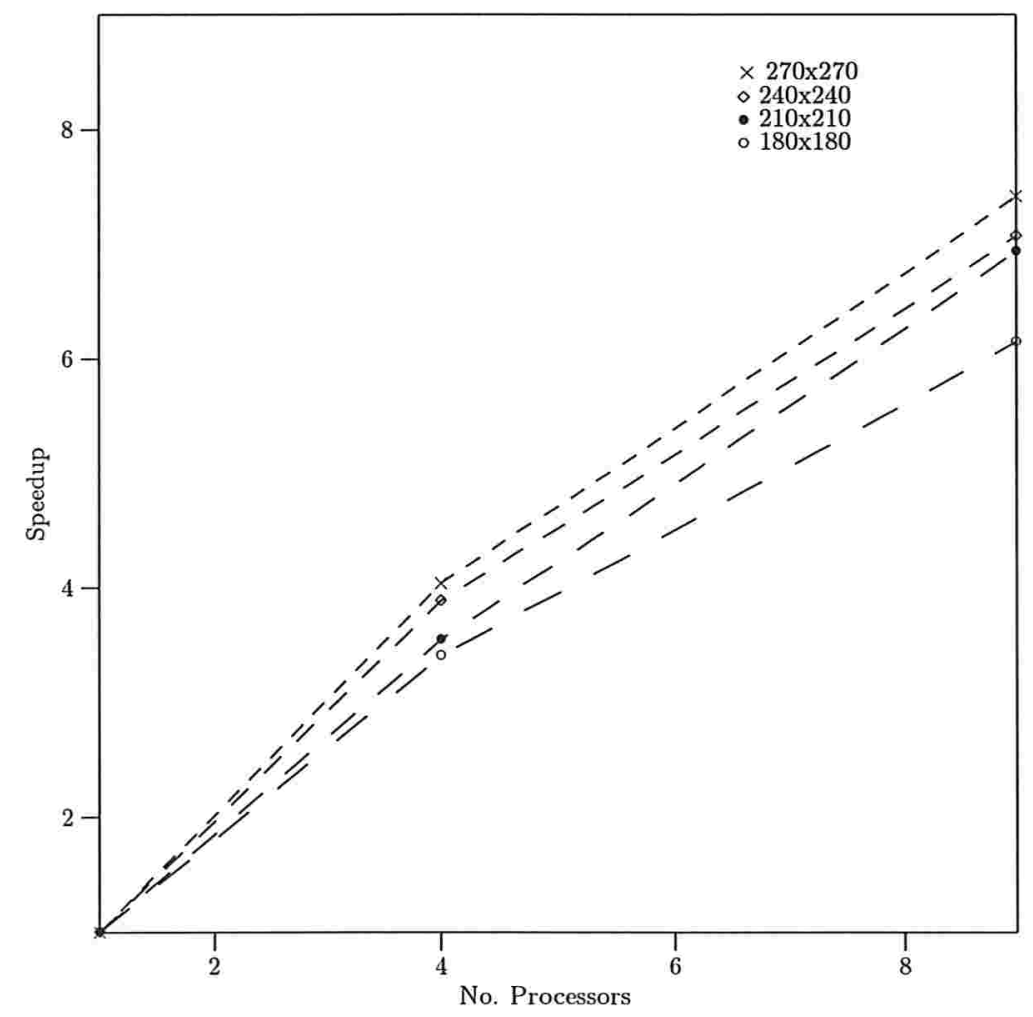

Figura 7.2: Speedups para Matrizes de Tamanho $180 \times 180$ a $300 \times 300$. 


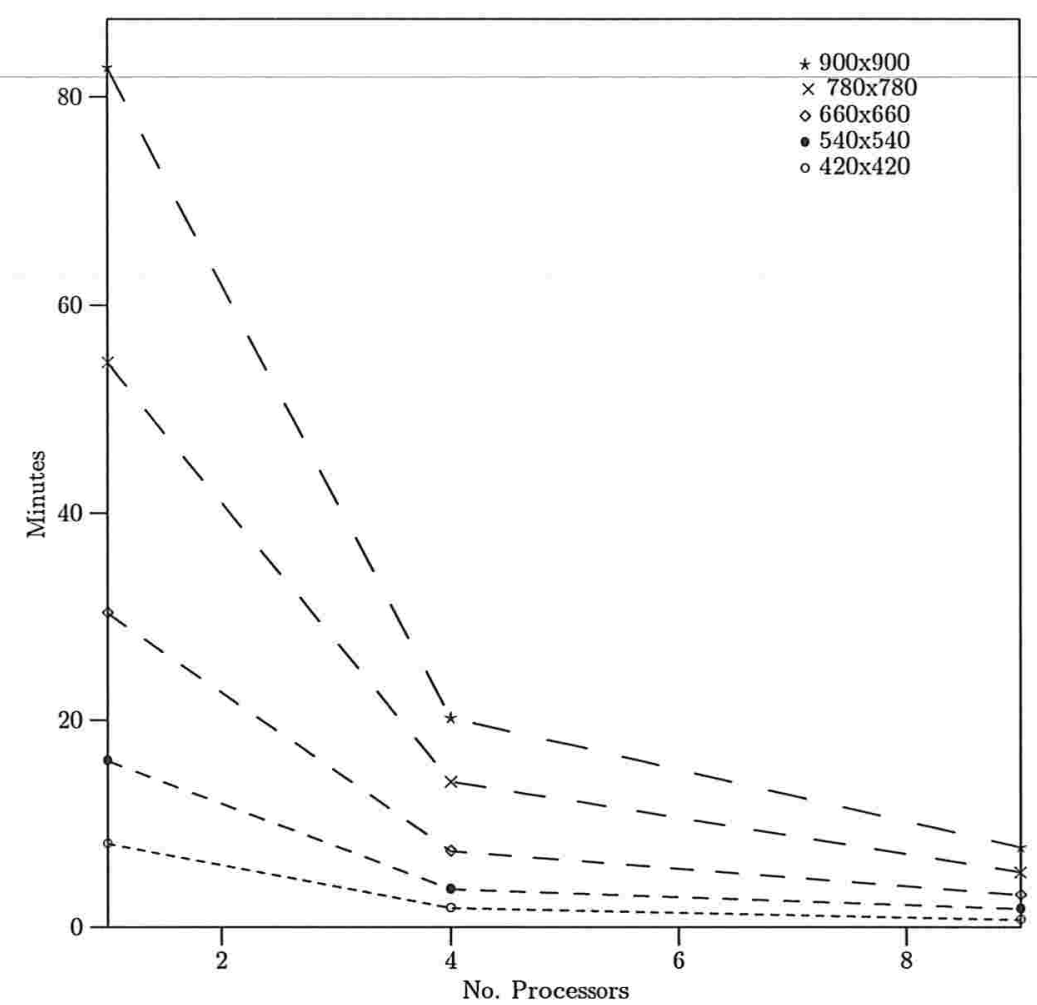

Figura 7.3: Tempo de Processamento para Matrizes de Tamanho $420 \times 420$ a 900 $\times 900$.

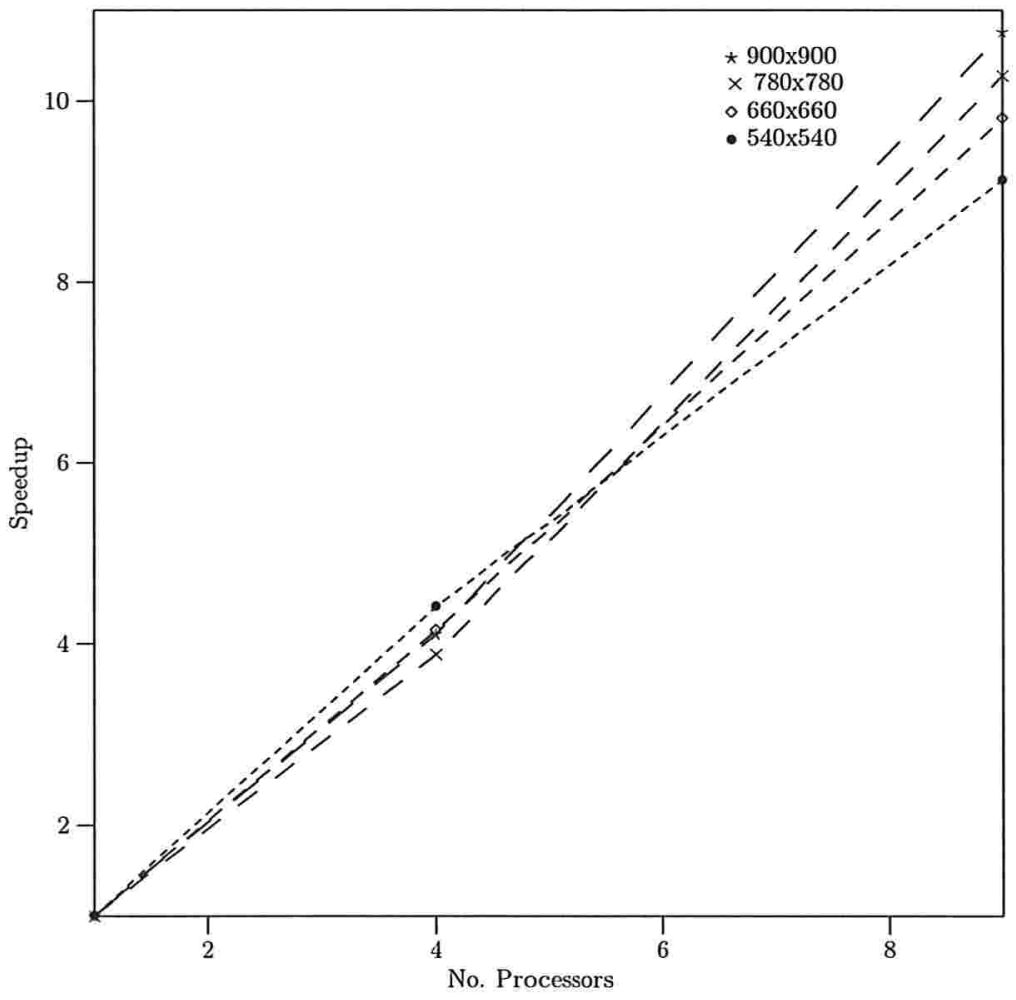

Figura 7.4: Speedups para Matrizes de Tamanho $420 \times 420$ a $900 \times 900$. 


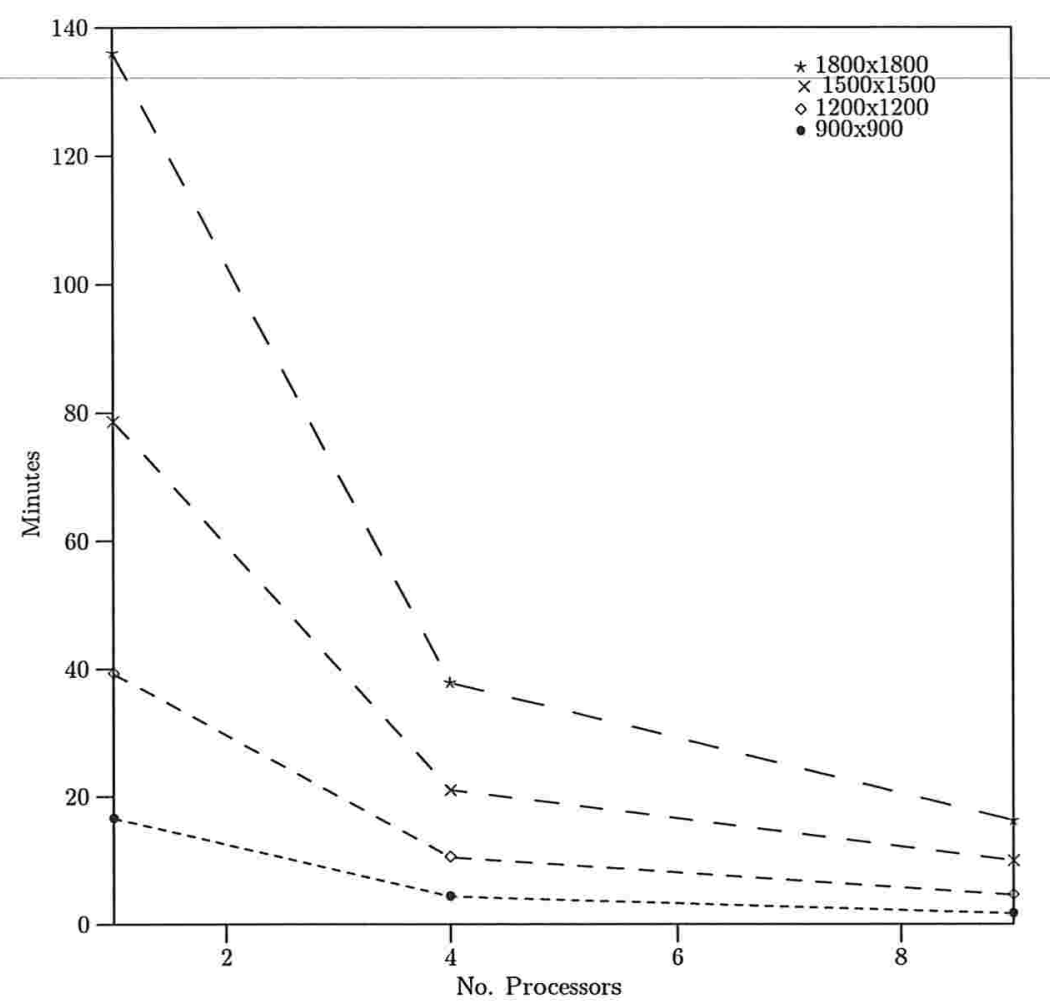

Figura 7.5: Tempo de Processamento para Matrizes de Tamanho $900 \times 900$ a 1800 $\times 1800$.

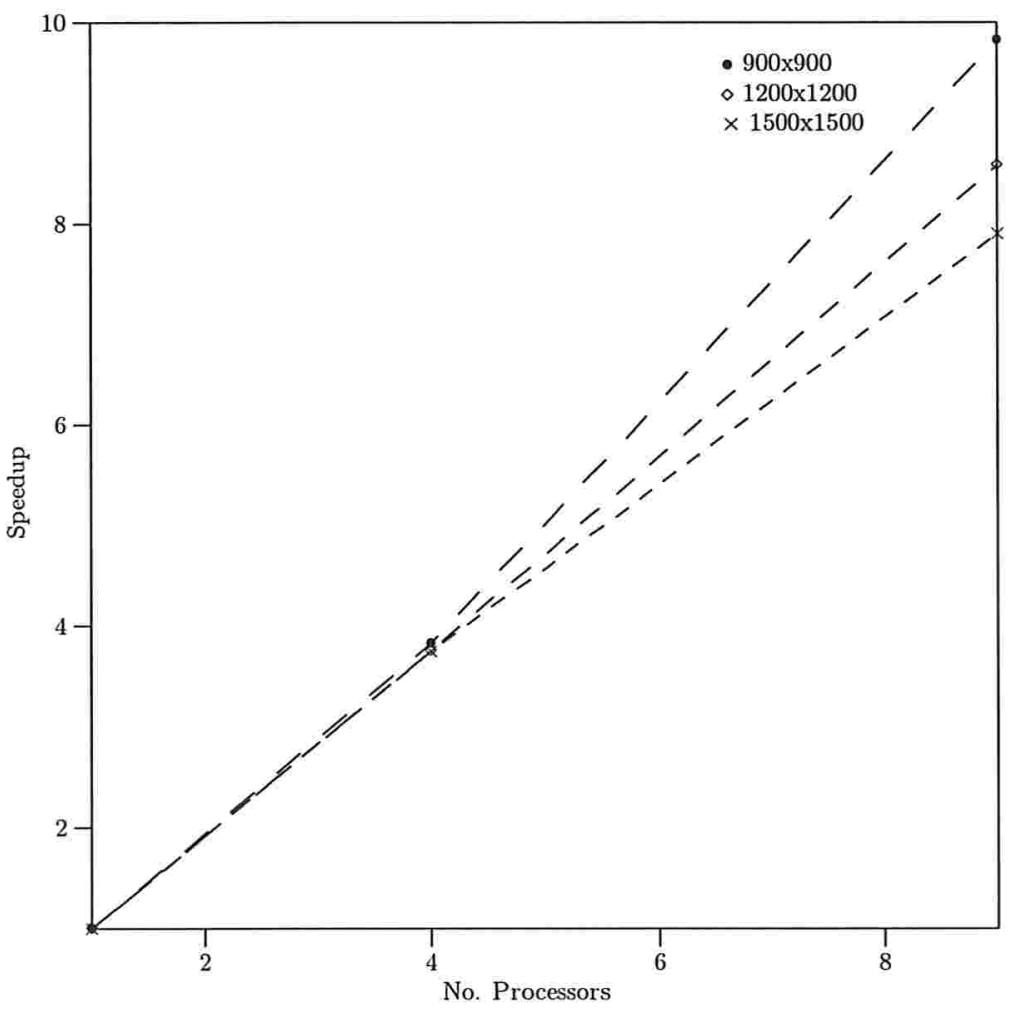

Figura 7.6: Speedups para Matrizes de Tamanho $900 \times 900$ a $1800 \times 1800$. 


\subsubsection{Na Grade de Desktops}

Para a grade de 18 desktops o algoritmo de multiplicação foi implementado tanto no modelo MPI como no BSP. Isso foi feito para comparar o desempenho do InteGrade, que usa o padrão BSP de Oxford, com o LAM-MPI. Ou seja, a prataforma de hardware é a mesma, o que muda é apenas o software utilizado. Pelos gráficos, nota-se que para 4 e 9 desktops há pouca diferença de desempenho entre o InteGrade e o BSP. Porém, a diferença aumenta consideravelmente para 16 desktops, com os speedups do gráfico do InteGrade caindo para valores menores do que para 9 desktops (ver figura 7.8), e portanto com o LAM-MPI ganhando nesse caso. Porém, notase que para 4 processadores, os tempos e speedups no InteGrade chegam a ganhar ligeiramente do LAM-MPI (ver figuras 7.8 e 7.10). Note que quanto maior o número de processadores, menor o tamanho da entrada do algoritmo para cada processador, pois as matrizes de entrada são divididas pelo número de processadores, obtendo-se submatrizes das matrizes de entrada. Dos testes, observou-se que o InteGrade ganha para menos processadores (4 e 9), e perde para mais processadores (16).

\section{Resultados no InteGrade}

Nas figuras 7.7 e 7.8 estão os tempos e speedups, respectivamente, para a implementação do algoritmo de multiplicação sobre o InteGrade. Note que para para 16 desktops os speedups diminuíram bastante, chegando a ser menores do que para 9 desktops. A queda de speedup fica mais evidente para matrizes menores, com o tamanho do grão ficando menor ainda. Nota-se que para 4 processadores, os tempos no InteGrade chegam a ganhar do LAM-MPI para as matrizes maiores.

\section{Resultados no LAM-MPI}

Nas figuras 7.9 e 7.10 estão os tempos e speedups, respectivamente, para o LAM-MPI. Particularmente, foi utilizado o LAM-MPI 7.7.1. Nota-se que o gráfico de speedup é mais estável do que o correspondente no InteGrade, com speedups nitidamente melhores para 16 desktops. 


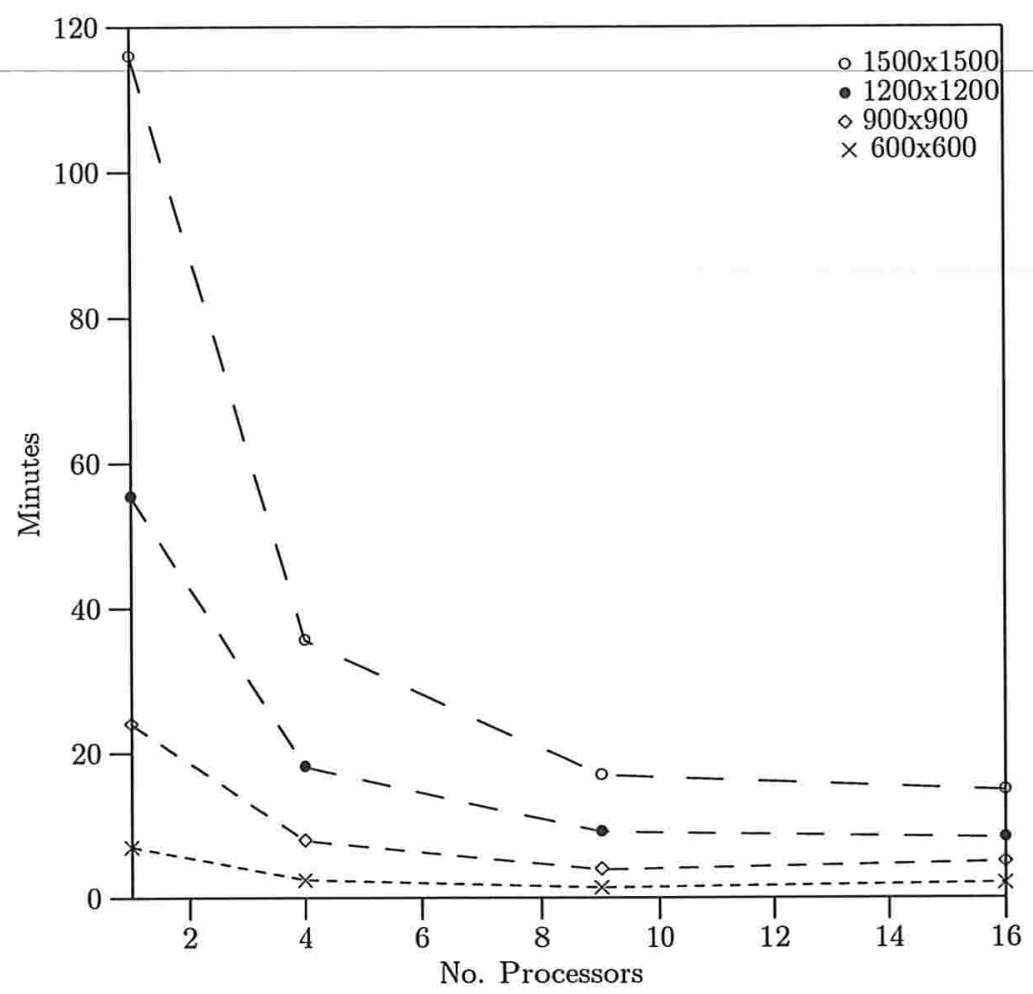

Figura 7.7: Tempos no InteGrade.

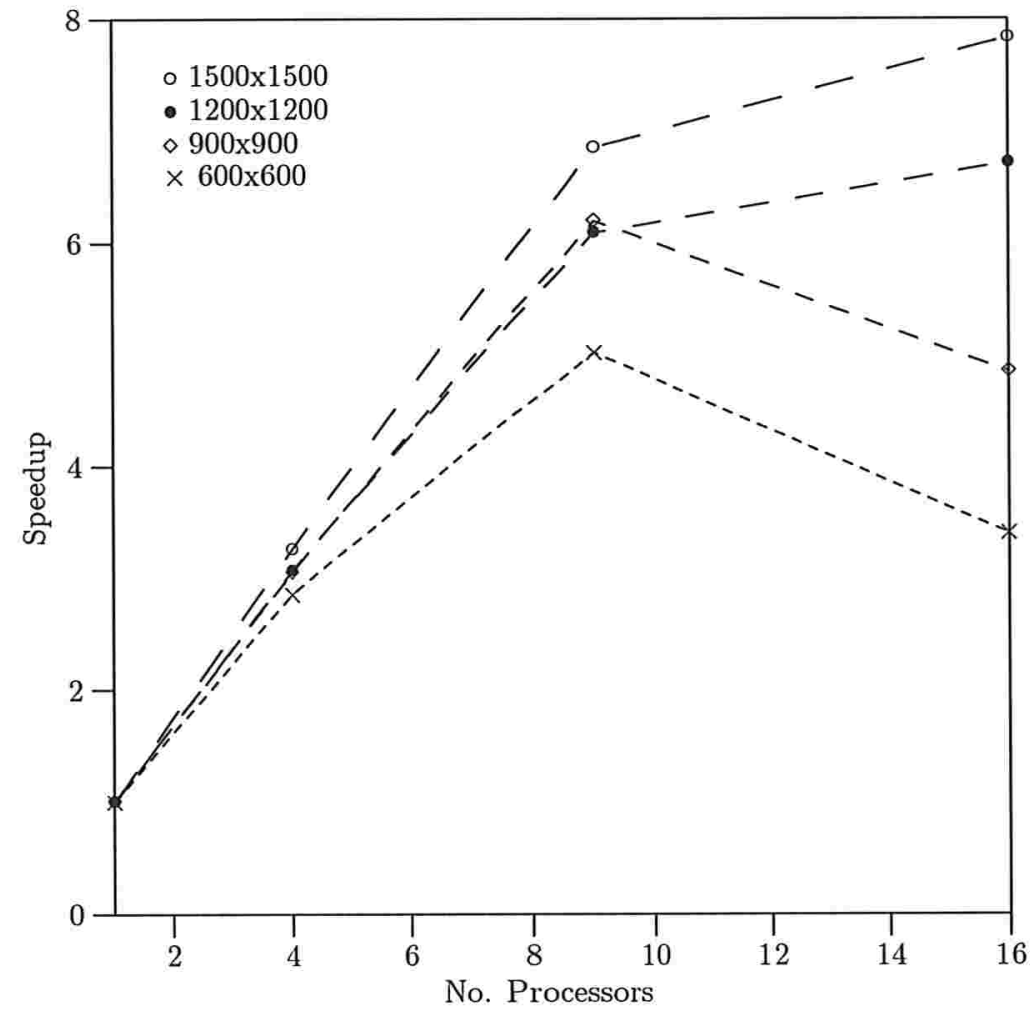

Figura 7.8: Speedups no InteGrade. 


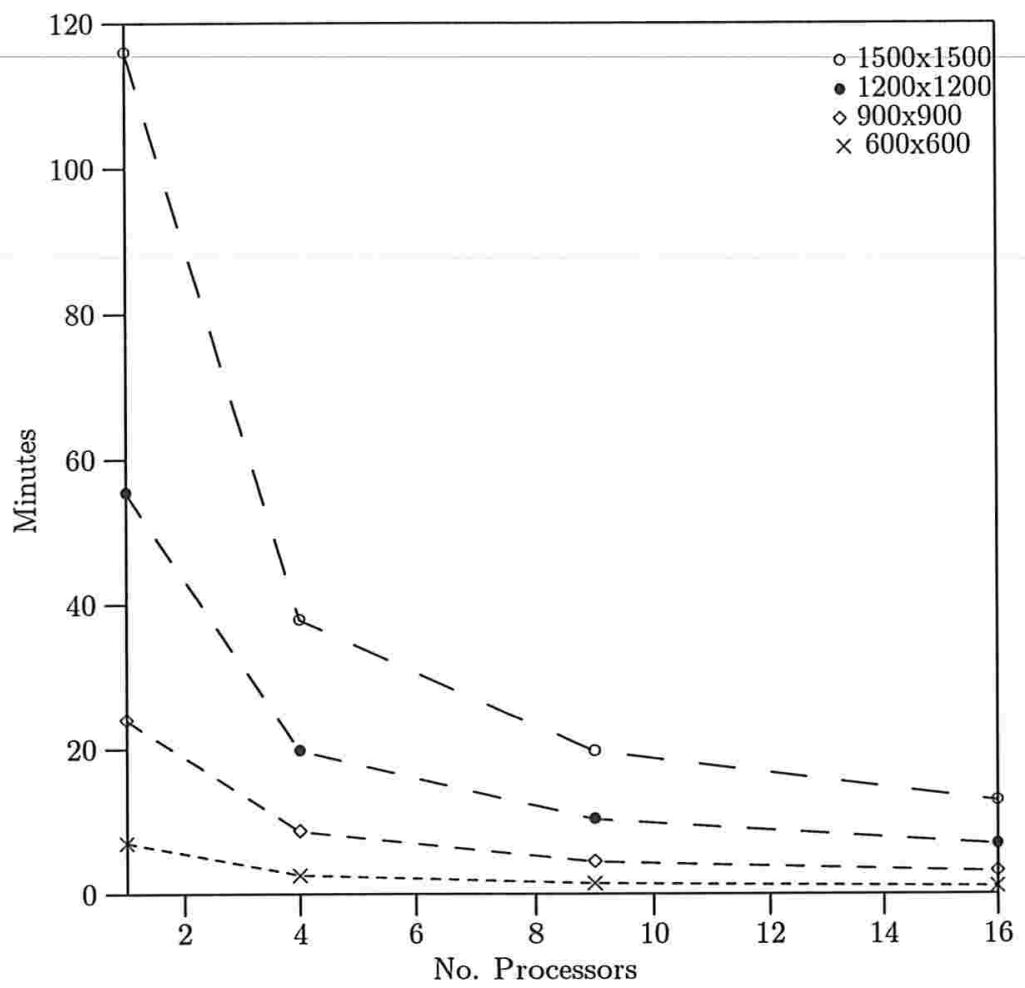

Figura 7.9: Tempos no LAM-MPI.

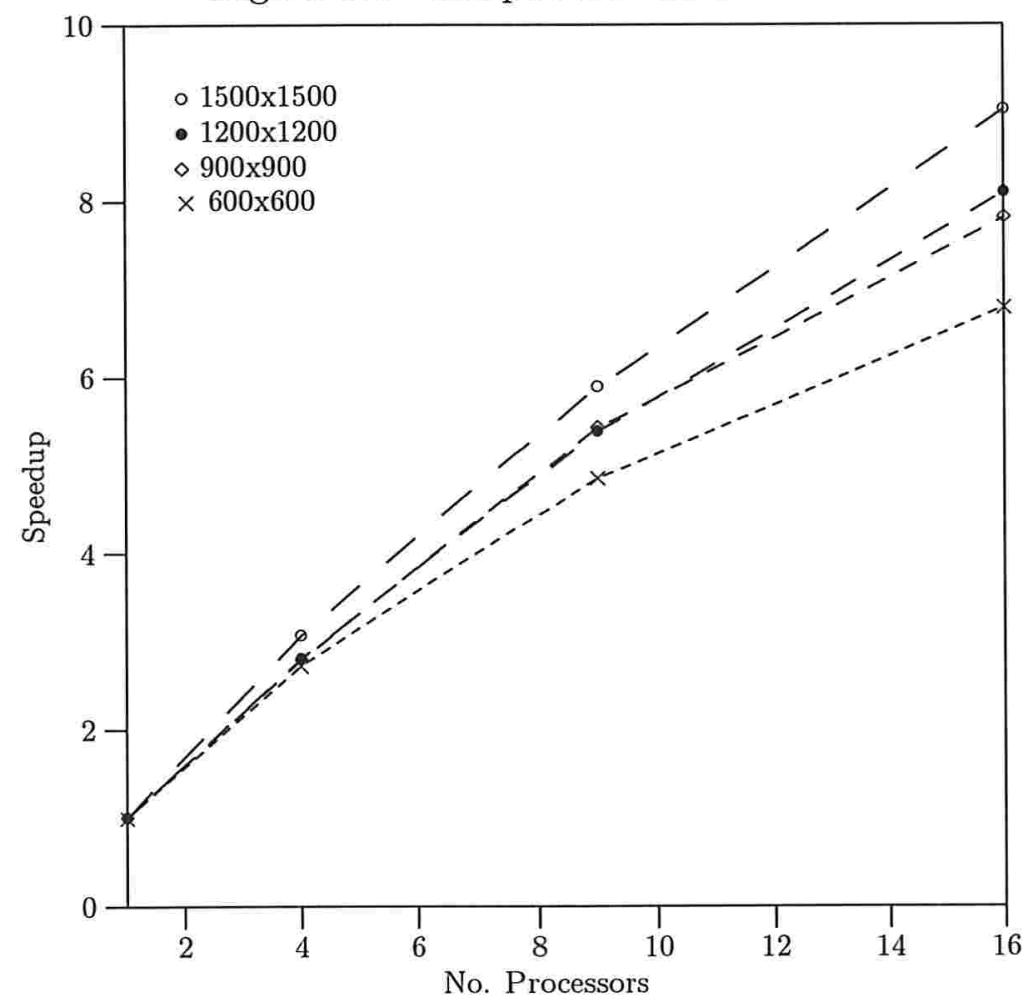

Figura 7.10: Speedups no LAM-MPI. 


\subsection{Similaridade ou Alinhamento de Cadeias}

O algoritmo de similaridade ou alinhamento de cadeias descrito no capítulo 6 foi implementado usando tanto os modelos MPI (Message Passing Interface) como o BSP (Bulk Synchronous Parallel). A seguir, serão mostrados os tempos e os speedups para as implementações no Beowulf usando LAM-MPI e depois para o InteGrade usando BSP.

\subsubsection{Resultados no Beowulf}

As figuras 7.11 e 7.12 mostram os tempos de processamento e speedups para 10 similaridades de duas cadeias de DNA de tamanho 4800 a 48000 . Note que para estes experimentos os speedups aumentam com o tamanho da matriz.

As figuras 7.13 e 7.14 mostram os tempos de processamento e speedups para 10 similaridades de duas cadeias de DNA de tamanho 72000 a 216000 . Aqui observamos o comportamento superlinear das curvas de speedup. 


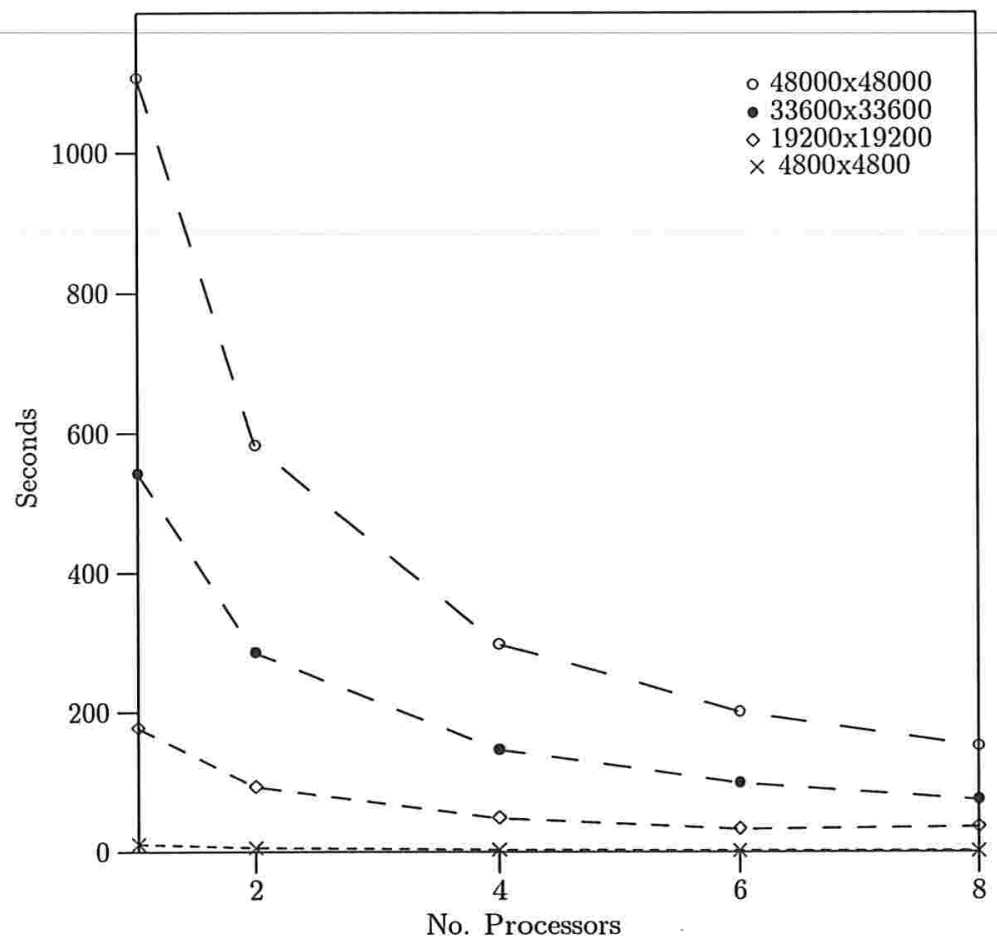

Figura 7.11: Tempos de Processamento para Cadeias de Tamanho 4800 a 48000.

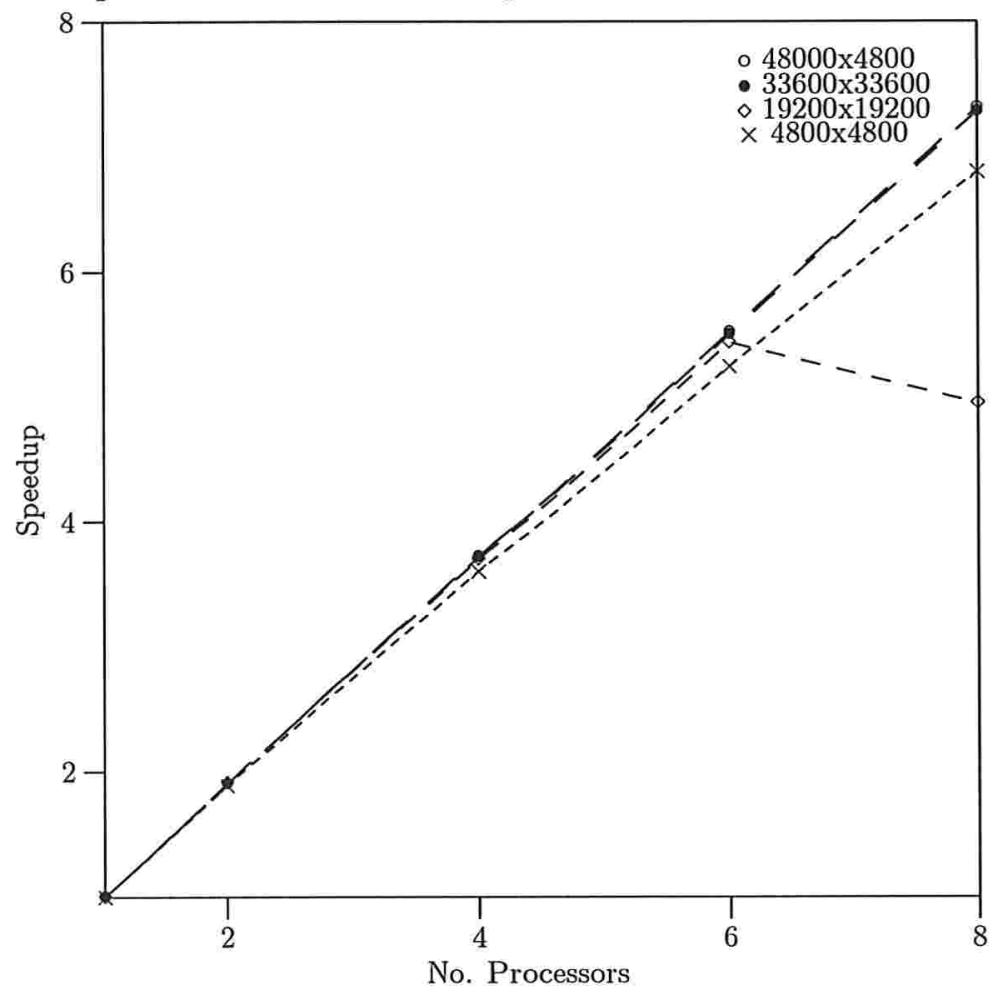

Figura 7.12: Curvas de Speedup para Cadeias de Tamanho 4800 a 48000. 


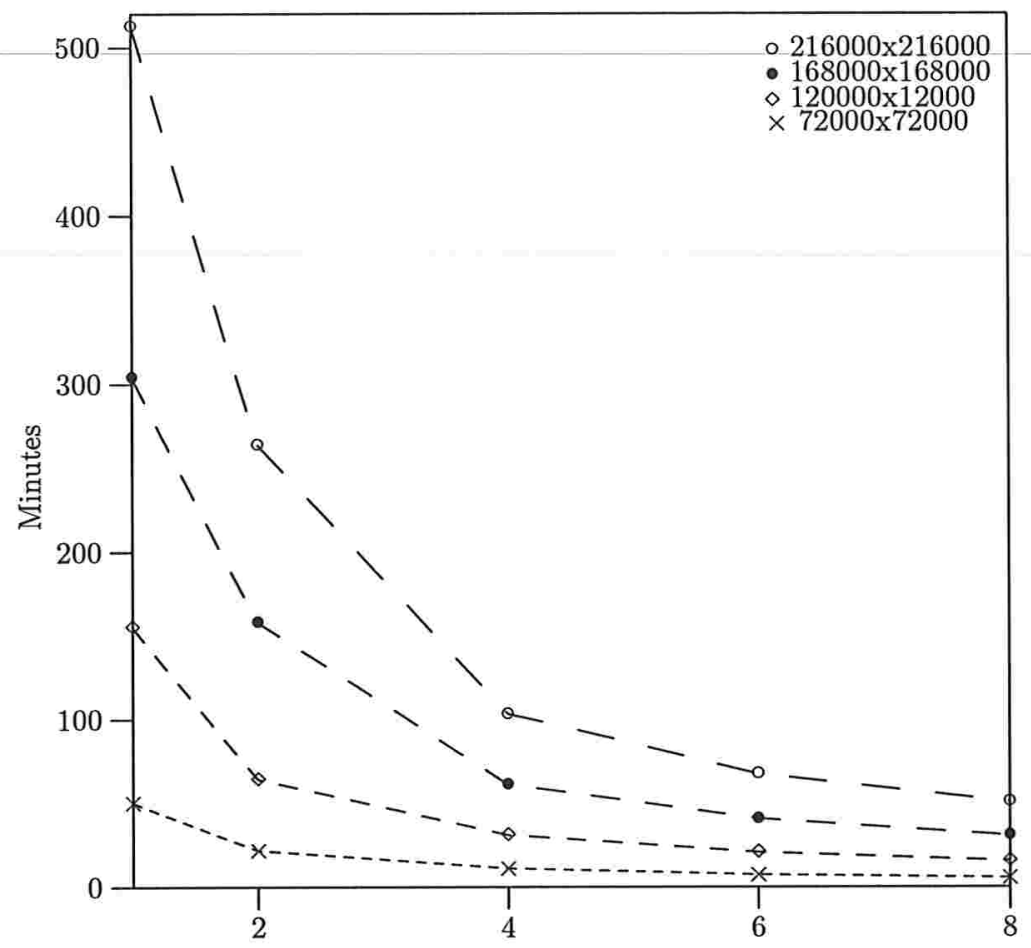

No. Processors

Figura 7.13: Tempos de Processamento para Cadeias de Tamanho 72000 a 216000.

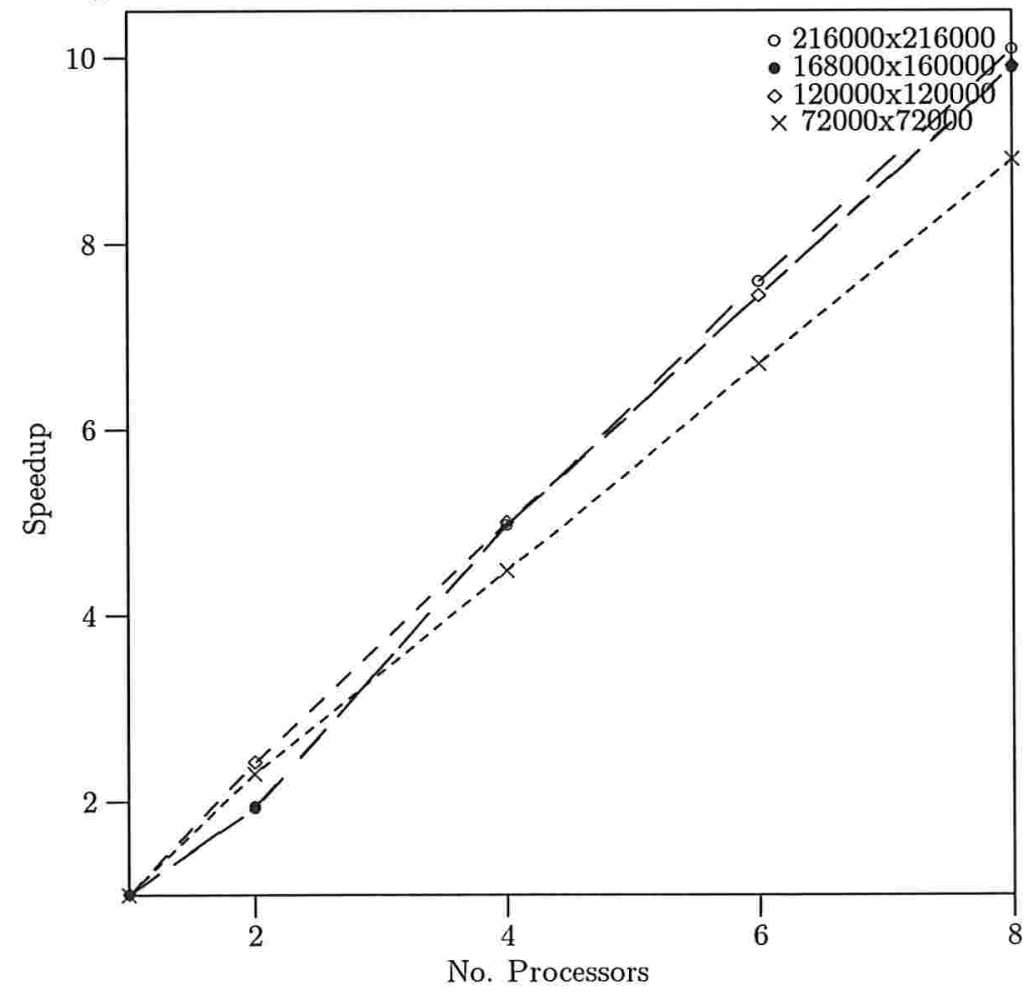

Figura 7.14: Curvas de Speedup para cadeias de tamanho 72000 a 216000 . 


\subsubsection{Resultados no InteGrade}

As figuras 7.15 e 7.16 mostram os tempos de processamento e speedups para 10 similaridades de duas cadeias de DNA de tamanho 12000 a 48000 usando o Integrade.

Foram feitos poucos testes no InteGrade, devido ao projeto InteGrade ser relativamente novo e apenas recentemente ter sido possível executar testes. Os speedups foram relativamente bons, próximos do speedup linear. 


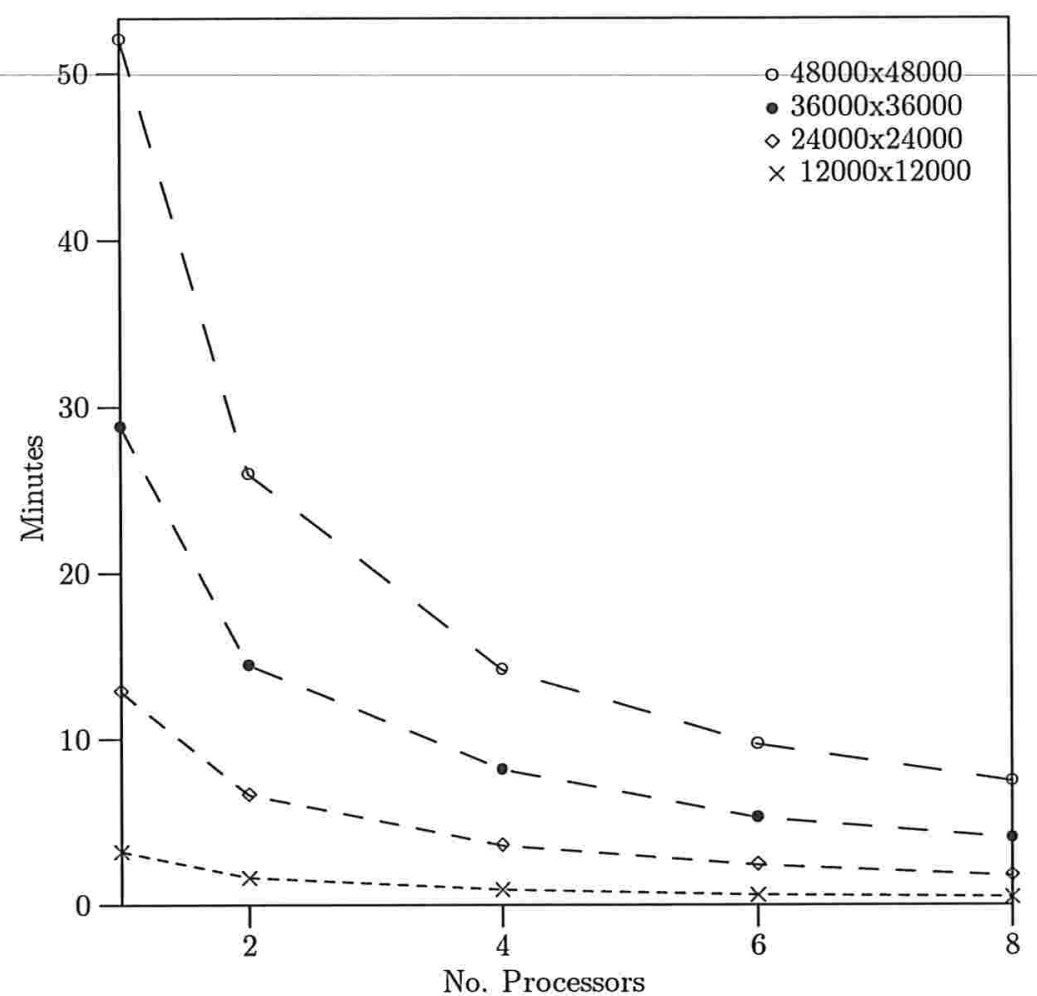

Figura 7.15: Tempos de Processamento para Cadeias de Tamanho 12000 a 48000.

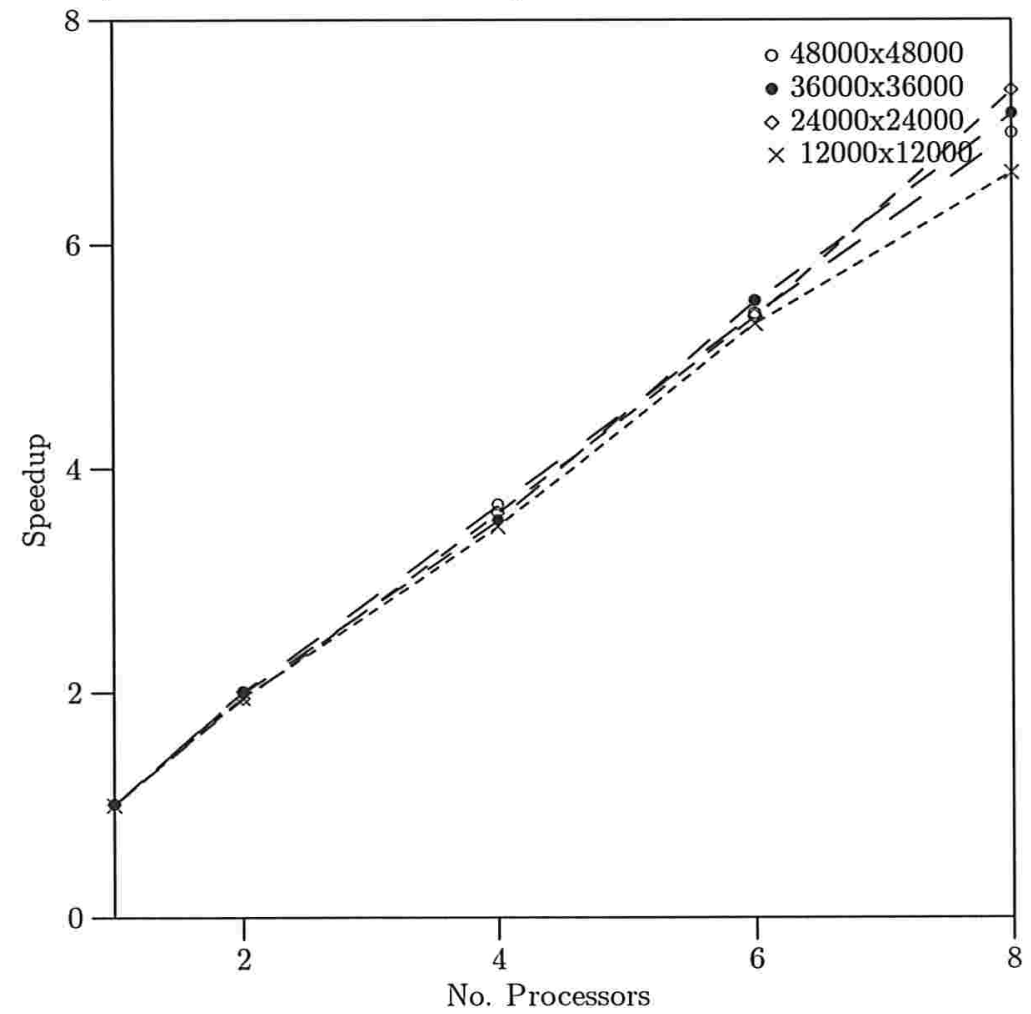

Figura 7.16: Curvas de Speedup para Cadeias de Tamanho 12000 a 48000 . 


\section{Capítulo 8}

\section{Conclusão}

Foi mostrado que usando o método de transformação de dependências do capítulo 4, originalmente proposto para o projeto de arranjos sistólicos para implementação de pastilhas de silício VLSI, podemos gerar algoritmos paralelos não triviais para aglomerados, após algumas adaptações. A adaptação consiste no envio de mensagens não bloqueante e recebimento de mensagens bloqueante, e em um ajuste para uma granularidade mais grossa. Ilustramos este método obtendo um algoritmo sistólico de multiplicação de matrizes, que pode ser usado para resolver as Trasnformadas de Legendre, muito usada nas computações da previsão do tempo através de multiplas multiplicações de matrizes em pipeline. Para $m$ multiplicações de duas $n \times n$ matrizes usando $p^{2}$ processadores, o algoritmo requer um total de $(m+1) p-1$ passos de computação e comunicação envolvendo submatrizes. O método proposto também foi aplicado ao problema de similaridade ou alinhamento de cadeias.

Usamos dois algoritmos bem conhecidos para ilustrar a método de transformação de dependências. O método é bem geral e pode ser usado para transformar algoritmos expressos como loops aninhados (multiplicação de matrizes e similaridade são apenas alguns deles). Também foi implementado o algoritmo de fecho transitivo, caminhos mínimos e convolução. Todos eles compartilhando as mesmas características de comunicação, e todos com poucos vizinhos.

O algoritmo de multiplicação de matrizes utilizado requer comunicação de cada processador com poucos vizinhos (quatro), ou seja, sem comunicação global. Um bom algoritmo paralelo para multiplicação de matrizes é dado em [44], mas ele é baseado em um broadcast de cada submatriz para todos os outros elementos da mesma linha ou coluna, exatamente o tipo de comunicação global que queremos evitar. 
Não fizemos nenhuma implementação para solucionar problemas como heterogêneidade e a tolerância a falhas. O problema da heterogêneidade deve ser tratado mesmo no caso de um cluster com computadores homogêneos, assumindo que pode haver uso aleatório de alguma das máquinas do cluster por um usuário qualquer. Uma idéia para solucionar esse problema seria usar um grupo de 2 ou mais computadores redundantes no lugar de cada elemento de processamento gerado pelo método proposto. Deste modo, o desempenho de um elemento de processamento será dado pela primeira máquina do grupo que realizar a tarefa. Note que com isto também provemos alguma tolerância a falhas, no sentido de que algumas máquinas do grupo podem cair, mas mesmo assim o processamento pode continuar nas outras máquinas, evitando substancialmente a perda de todas as computações realizadas.

Alguns ambientes de grade de computação tem middlewares especiais que provêem tolerância a falhas, como no projeto InteGrade [28], que tem como um dos objetivos a construção de um middleware que forneça tolerância a falhas via checkpointing.

O algoritmo seqüencial de multiplicação de matrizes requer $p^{3}$ passos de computação envolvendo $n / p \times n / p$ submatrizes. Obtivemos um speedup em termos de passos de computação de $\frac{m p^{3}}{(m+1) p-1}$ ou aproximadamente $p^{2}$. Como estamos usando $p^{2}$ processadores, obtemos speedup linear.

Os algoritmos de multiplicação de matrizes e similaridade ou alinhamentode cadeias foram rodados em um Beowulf de 16 nós, com microprocessadores de baixo custo. No caso de multiplicação de matrizes, foram testados matrizes de tamanho $180 \times 180$ a $1800 \times 1800$, e no caso de similaridae ou alinhamento de cadeias, cadeias de tamanho 4800 a 216000 .

\subsection{Trabalhos Futuros}

Futuramente pretende-se solucionar os problemas que ficaram pendentes, que são a heterogeneidade e tolerância a falhas, caso já não tenham sido solucionados por outro trabalho. Para isso sugere-se o estudo de novas bibliotecas de computação paralela que possam ter soluções para tais problemas, assim como o estudo mais profundo das atuais bibliotecas existentes. O LAM-MPI por exemplo tem uma série de funções que ainda não foram estudadas, havendo centenas de funções. O BSPlib de Oxford é uma biblioteca relativamente recente, e vem crescendo ultimamente, com novas funções sendo adicionadas. 
Como as bibliotecas para MPI e BSP apenas seguem modelos de computação paralela, nada impede que o problema seja resolvido implementando-se novas funções que solucionem os problemas de heterogeneidade e tolerância a falhas. Para tal, estudaria-se a fundo as implementações das atuais bibliotecas de computação paralela.

Além dos problemas pendentes, pretende-se estudar outros métodos de paralelização. Além disso, um estudo de sistemas distribuídos ajudaria a implementar novas funções para os atuais modelos de computação paralela.

Pretende-se também adicionar mais implementações, tais como Transformações LU e Sistemas Lineares. Com o método proposto neste trabalho, pode-se implementar qualquer algoritmo que contenha laços aninhados. Pretende-se fazer melhorias nas atuais implementações, pois elas oferecem poucas opções de customização. Também visa-se a elaboração de manuais mais detalhados para os programas. 


\section{Referências Bibliográficas}

[1] Edson Norberto Cáceres, Henrique Mongelli e Siang Wun Song. "Algoritmos Paralelos usando CGM/PVM/MPI: Uma Introdução". Texto preparado para o XXI Congresso da Sociedade Brasileira da Computação, Jornada de Atualização em Informática, Fortaleza, julho de 2001, pp. 219-278.

[2] E. Eliasen, B. Machenhauer, and E. Rasmussem. On a numerical method for integration of hydrodynamical equations with a spectral representation of the horizontal fields. Technical Report No. 2, Copenhagen University, Institute of Theoretical Meteorology, 1970. 35 páginas.

[3] S. A. Orszag. Transform methods for calculation of vector coupled sums: Application to the spectral form of the vorticity equation. "Journal Atmospheric Science", 27:890-895, 1970.

[4] OMG. CORBA v3.0 Specification. Object Management Group: Needham, MA, July 2002. OMG document 02-06-33.

[5] Cosnard, M., Quinton, P., Robert, Y. and Tchuente M. (editors) "Parallel Algorithms and Architectures". North Holland, 1986.

[6] Fortes, J. A. B. and Moldovan, D. I. "Parallelism detection and transformation techniques useful for VLSI algorithms". Journal of Parallel and Distributed Computing 2, p. 277-301, 1985.

[7] Foster, M. J. and Kung, H. T. "The design of special-purpose VLSI chips". Computer, 13, p. 26-40, 1980.

[8] Karp, R. M., Miller, R. E. and Winograd, S. "The organization of computations for uniform recurrence equations". Journal of the ACM, 14, p. 563-590, 1967.

[9] Kung, H. T. "Let's design algorithms for VLSI systems". Proceedings of Caltech Conference on VLSI, p. 65-90, January, 1979. 
[10] Kung, H. T. and Leiserson, C. E. "Systolic arrays for VLSI", in: Introduction to VLSI Systems, C. A. Mead and L. A. Conway, Chapter 8.3, Addison-Wesley, 1980 .

[11] Kung, H. T. "The structure of parallel algorithms". Advances in Computing, 19, p. 65-111, 1980.

[12] Kung, H. T. "Why systolic architectures". Computer, 15, p. 37-46, 1982.

[13] Okuda, Kunio and Song, Siang W. "Um Algoritmo de Multiplicação de Matrizes para implementação em VLSI". Anais do I Congresso da Sociedade Brasileira de Microeletrônica, Campinas, pp. 383-393, 1986.

[14] Polychronopoulos, C. D. "Compiler optimization for enhancing parallelism and their impact on architecture design". IEEE Transactions on Computers, Vol. 37, No. 8, August 1988, pp. 991 - 1004.

[15] Quinton, P. "The systematic design of systolic arrays", in:Automata Networks in Computer Science, F. Fogelman, Y. Robert and M. Tchuente (editors), Manchester University Press, p. 229-260, 1987.

[16] Quinton, P. and Robert, Y. Algorithmes et architectures systoliques. Masson, Paris, 1989.

[17] Ribas, H. B. "Automatic Generation of systolic programs from nested loops", Ph.D. thesis, Department of Electrical and Computer Engineering, Carnegie Mellon University, June, 1990.

[18] Robert, Y. "Systolic algorithms and architectures", in: Automata Networks in Computer Science, F. Fogelman, Y. Robert and M. Tchuente (editors), Manchester University Press, p. 187-228, 1987.

[19] Robert, Y. "Systolic algorithms \& architectures", chapter 1,2,3,6. Prentice Hall International(UK) Ltd, 1991.

[20] Shang, W., O'Keefe, M. T. and Fortes, J. A. B. "On loop transformations for generalized cycle shrinking". Proceedings of International Conference on Parallel Processing, August 1991, pp. II-132 - II-141.

[21] Shang, W., O'Keefe, M. T. and Fortes, J. A. B. "Generalized cycle shrinking", in: Parallel Algorithms and VLSI Architectures II, P. Quinton and Y. Robert (editors), North Holland, 1991. 
[22] Weiser, U. and Davis, A. "A wavefront notation tool for VLSI array design", in:VLSI Systems and Computations, H. T. Kung et al. (editors), p. 226-234, Computer Science Press, 1981.

[23] Wolfe, M. "Optimizing Supercompilers for Supercomputers". MIT Press, Cambridge MA, 1989.

[24] Young, D. M. "em Iterative Solution of Large Linear Systems". Academic Press, 1971.

[25] Foster I. and Kesselman K. "The Grid: Blueprint for a new Computing Structure",chapter 2,3,5,11. Morgan Kaufmann Publishers, 1999.

[26] Cirne, W. "Grids Computacionais: Arquiteturas, Tecnologias e Aplicações". Anais do terceiro Workshop em Sistemas Computacionais de Alto Desempenho. Outubro de 2002.

[27] Goldchleger, A., Kon F., Lejbman A. G., Finger M. and Song S. W. "Integrade: Rumo a um Sistema de Computação em Grade para Aproveitamento de Recursos Ociosos em Máquinas Compartilhadas". Technical Report MAC-IME-USP 2002-08, October 2002.

[28] Andrei Goldchleger, Fabio kon, Alfredo Goldman, Marcelo Finger, and Germano Capistrano Bezerra. Integrade:Object-Oriented Grid Middleware Leveraging Idle Computing Power of Desktop Machines. "Concurrency and Computation: Practice and Experience",16:449-459, March 2004.

[29] Song, S. W. "Síntese de algoritmos paralelos para o n-cubo binário". Tese apresentada ao Instituo de Matemática e Estatística da universidade de São Paulo.

[30] Evans D. J. "Systolic Algorithms". Gordon and Breach Science Publishers, 1991.

[31] Seti@home. "The Search for Extraterrestrial Intelligence". http://setiathome.ssl.berkeley.edu.

[32] Site do Grid Forum. http://www.gridforum.org.

[33] Foster, I. and Kesselman K. "The Grid: Blueprint for a new Computing Structure", chapter 2,3,5,11. Morgan Kaufmann Publishers, 1999.

[34] Megson G. M. and Evans D. J."Algorithmic fault tolerance for matrix operations on triangular arrays". Elsevier Science Publishers, 1989. 
[35] Site do Beowulf do IME-USP. http://www.vision.ime.usp.br/ cage/Beowulf.

[36] Departamento de Ciência da Computação do IME/USP.

[37] Site do projeto IMPAR. http://www.ime.usp.br/ song/impar.

[38] Site do projeto Globus. http://www.globus.org.

[39] Condor. Sítio do projeto Condor,2004.

http://www.cs/wisc/edu/condor/

[40] Litzkow M., Livny M. and Mutka M. Condor - A Hunter of Idle Workstations. In "Proceedings of the 8th Internacional Conference of Distributed Computing Systems", pages 104-111, June 1988.

[41] Legion. Sítio do projeto Legion. http://www.cs.virginia.edu/ legion/,2004.

[42] BOINC. Sítio do projeto boinc, 2004. http://boinc.berkeley.edu.

[43] Natrajan A., Humphrey $M$ and Grimshaw A. Grids: Harnessing Geographically-Separated Resources in a Multi-Organisational Context. Presented at High Performance Computing Systems, June 2001.

[44] G. Fox. "Solving Problems on Concurrent Processors". Prentice Hall,1988.

[45] GIMPS. The Great Mersenne Prime Search. http://www.mersenne.org/.

[46] Dicionário On-line de termos técnicos http://webopedia.internet.com/TERM/M/Moores_Law.html

[47] B. Wilkinson and M. Allen. "Parallel Programming - Techniques and Aplications Using Network Workstations and Parallel Computers". Prentice Hall, 1999.

[48] Ver site http://www.top500.org

[49] Alves, C. E. R., Cáceres, E. N., Dehne, F., and Song, S. W. A Parallel Wavefront Algorithm for Efficient Biological Sequence Comparison. The 2003 International Conference on Computational Science and its Applications - ICCSA 2003. Lecture Notes in Computer Science, Vol. 2668, Kumar, V.; Gavrilova, M. L.; Tan, C.J. K.; L'Ecuyer, P., (Eds.), Springer-Verlag. Montreal, Canada, May 18-21, 2003, pp. 249-258.

[50] Site da rede LCPD. http://www.lcpd.ime.usp.br 
[51] Site da rede Eclipse. http://www.eclipse.ime.usp.br

[52] LAM/MPI. http://www.lam-mpi.org

[53] BSP de Oxford. http://www.bsp-worldwide.org/implmnts/oxtool.htm 